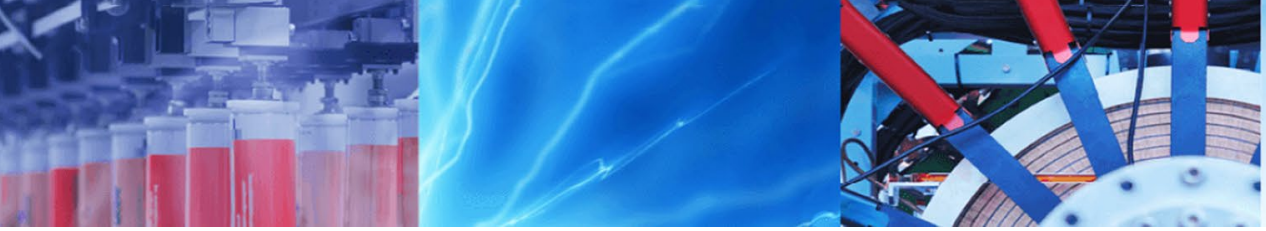

Research Article

\title{
A two-stage fuzzy multi-criteria approach for proactive maintenance strategy selection for manufacturing systems
}

\author{
Desmond Eseoghene Ighravwe ${ }^{1} \cdot$ Sunday Ayoola Oke ${ }^{2}$ ID
}

Received: 3 February 2020 / Accepted: 3 September 2020 / Published online: 12 September 2020

(c) Springer Nature Switzerland AG 2020

\begin{abstract}
This paper studies the use of fuzzy logic theory embedded in fuzzy axiomatic design to develop an integrated model with the analytical hierarchy process, and a selection of maintenance strategies in manufacturing systems through weighted sum-product evaluation. In this paper, an analysis was conducted to understand the model characteristics of combined fuzzy axiomatic design, analytic hierarchy process and weighted aggregated sum product assessment. The results from the analysis served as information to establish the best maintenance strategy. Based on the data obtained from a factory, which was tested on the proposed framework, it is concluded that the most preferred proactive maintenance strategy for the case study was preventive maintenance, followed by reliability-based maintenance while predictive maintenance is the least preferred maintenance strategy in the rolling mill. Accordingly, the two-stage fuzzy multi-criteria maintenance strategy selection approach is appropriate to select the best maintenance strategy for the factory. This paper offers a new method to establish the best maintenance strategy for a rolling mill. As such, the manager could install a method for significant improvement in engineering practices with promising business excellence and competitiveness results.
\end{abstract}

Keywords Maintenance $\cdot$ Decision making $\cdot$ Manufacturing $\cdot$ Optimisation

\section{Introduction}

Manufacturing systems operate on the premise of many factors - how much demand for the product is desired? What speed of production should be applied and to what product uniqueness will guarantee sales? [1, 2]. Examples of manufacturing systems include assembly lines [3], intermittent [4], just-in-time [5], batch production [6-8], reconfigurable [9], lean manufacturing [10], custom, flexible [11] and computer-integrated manufacturing [12]. From these examples, manufacturing systems is strongly hinged on the arrangement and strategic management of equipment, labour, materials, information and tools. However, the maintenance function is the backbone of manufacturing systems that should be carefully planned in terms of strategy $[13,14]$. A maintenance strategy refers to regulations of order for the scheduled maintenance, including predictive maintenance, reliability-centred maintenance, run-to-fail and preventive maintenance [15-18]. The appropriate selection of a maintenance strategy is critical and a very strong determinant of the manufacturing system's success [19]. It improves performance and competitiveness in the marketplace.

However, on the literature regarding maintenance strategy formulation, there are very scanty experiences and contributions in research and practice to discuss [15, $16,20]$. Furthermore, merely a few articles are associated with strategy selection in manufacturing plants, and no articles of substantial importance have been proposed to select the maintenance strategy of a rolling mill in a developing country within a proactive context [21-23]. Also, considering all the multicriteria analysis methods none is in the public domain, which has integrated the analytic hierarchy process (AHP) and weighted

$\triangle$ Sunday Ayoola Oke, sa_oke@yahoo.com | 'Department of Mechanical and Biomedical Engineering, Bells University of Technology, Ota, Nigeria. ${ }^{2}$ Department of Mechanical Engineering, Faculty of Engineering, University of Lagos, Akoka-Yaba, Lagos, Nigeria. 
aggregated sum product assessment (WASPAS) and used to solve problems on strategy selection in rolling mills. More unfortunate is the knowledge gap that exists considering the integration of AHP and WASPAS; there is a deficiency in knowledge on any study which has exploited the unique context of uncertainty and imprecision on maintenance strategy while combining AHP and WASPAS. This paper studies the use of fuzzy logic theory embedded in fuzzy axiomatic design (FAD) to develop an integrated model with analytic hierarchy process, and a selection of maintenance strategies in manufacturing systems through weighted sum-product evaluation.

Consequently, the selection of an appropriate maintenance strategy is crucial to align maintenance resources. By deploying multicriteria models to the maintenance selection practice in rolling mills several workers (hot and cold mill engineers, hot working metallurgists, maintenance engineers and process managers) will have their expertise compared and exploited to benefit the rolling mill. Using multicriteria models (AHP, WASPAS and FAD) to analyse the maintenance strategy problem for the rolling mill offers understanding into the various judgements of the respondents' values. The obtained scores and weights in the analysis of maintenance strategy are therefore useful as a reference. As such, the use of multicriteria models, and the fuzzy axiomatic design infused into multicriteria models should attract researchers and practising maintenance managers in the industry. Unfortunately, in the present circumstance, maintenance scholars have emphasized the simulation and predictive characteristics of maintenance strategy models in crisp numeric values. However, studies regarding uncertainty and imprecision details have been limited and no single study appears to have been reported on rolling mills regarding maintenance strategy selection.

This article utilises fuzzy axiomatic design to integrate the AHP and WASPAS for a rolling mill in Nigeria because of its outstanding characteristics. First, FAD highlights an effective decision process in maintenance, and the maintenance manager can choose the best strategy through task establishment, task sequence adjustment and mapping of maintenance resources to equipment effectively. Concurrently, FAD brings competitive advantage, reduced failure risk and reduced maintenance expenses. The case study focused on the plant, whose main outputs are sheets (plain and patterned), coils (stucco and special rolled) and circles. Through a questionnaire approach with ethical compliance, the necessary elements and parameters, which served as inputs into the selection methodology, was generated. The FAD analyzed the functional and design requirements into criteria for maintenance system performance as well as maintenance system design, respectively.

\section{SN Applied Sciences}

Furthermore, maintenance strategy selection has been a principal research topic in the maintenance literature for at least 15 years now [20, 24-28]. Wind turbines have been studied to create a fuel resource mechanism to transfer kinetic to electrical energy and avoid atmospheric emissions that produce greenhouse gases [24]. Andrawus et al. [24] established and appraised situationcontrolled maintenance tasks regarding the life phase of the wind turbine to exploit return-on-investment in wind plants.

However, due to the novel concept of proactive selection of maintenance strategies in manufacturing systems as a new research concept, extremely restricted studies have been conducted so far to analyse selection strategies in particular industries. Ilangkumaran and Kumanan [19] chose the utmost maintenance strategy for the textile industry by coupling TOPSIS with AHP. Furthermore, Ding et al. [29] optimized maintenance strategy in a palm oil production and revealed that preventive maintenance was the candidate strategy to limit system failures. Vishnu and Regikumar [30] selected a reliabilitymotivated strategy with a test-case from a manufacturing plant producing titanium dioxide up to a limit of 20,000 metric tones per year.

Apart from the literature that treats specific applications, several other studies were successfully conducted and reported in the literature and some of the include Bashiri et al. [31], Bertolini and Bevilacqua [32], Fouladgar et al. [33], Gaonkar et al. [34], llangkumaran and Kumanan [35], Jafari et al. [36], Pariazar et al. [37], Sagar et al. [38], Wang et al. [39], Zaeri et al. [40] and Zain et al. [41].

A literature search was conducted from a multidisciplinary viewpoint to establish the research gap for the present work. The diverse areas studies include aerodynamics, wind energy, thermal sciences, marine engineering and manufacturing industry. This results in the following observations and gaps:

- Early investigators studied the following areas: aircraft systems [20], wind turbines [24], rolling stock (railway vehicles; [25]), thermal power plants [28], gas turbine plant [26] and naval ships [27].

- Maintenance strategy selection is comparatively new in manufacturing systems and has very limited reports.

- Studies on rolling mills are missing in maintenance selection research. But rolling mills produce products (i.e. channel stock, angle stock, and I-beams, rails and bar stock) for other manufacturing plants, making it important.

- No process plant in Nigeria appears to have been studied regarding maintenance strategy selection process for improvement. 
- No single study was found on the innovative method of WASPAS, fuzzy axiomatic design and AHP for the selection of maintenance strategy in rolling plants.

From the foregoing, regarding novelty, this is probably the first article to apply fuzzy multi-criteria in a rolling mill. It takes a developing country's context to analyse strategy selection for maintenance in an innovative manner. The fuzzy axiomatic design, analytical hierarchy process and WASPAS were integrated for the first time in a rolling mill to solve the maintenance strategy selection problem, uniquely. Thus, the maintenance engineer could make a sound decision on the choice of appropriate strategy in the global competitive rolling mill industry.

The next parts of the paper are arranged in the following ways. In Sect. 2, the research methodology that was adopted for the selection process is described. The inferences obtained from the study results are highlighted in Sect. 3 with the display of results preceding it. Section 4 discusses the contributions, managerial implications, limitations and future research. The last section, Sect. 5 provides concluding remarks on the subject.

\section{Research methodology}

In manufacturing systems, preventive $\left(A_{1}\right)$, predictive $\left(A_{2}\right)$ and reliability-based $\left(A_{3}\right)$ maintenance strategies are among the most used proactive maintenance strategies for facility maintenance $[17,18]$. Their importance varies from one manufacturing system to another. To provide an empirical approach for the selection of a proactive maintenance strategy for a manufacturing system this study proposes Fig. 1. The descriptions of the various techniques in Fig. 1 are based on some of the following notations.

\begin{tabular}{ll}
\hline AD & Axiomatic design \\
SA & System area \\
CR & Common range \\
SR & System range \\
DP & Design requirements \\
FR & Functional requirements \\
TrFN & Trapezoidal fuzzy number \\
$A_{1}$ & Predictive maintenance \\
$A_{2}$ & Preventive maintenance \\
$A_{3}$ & Reliability-based maintenance \\
\hline
\end{tabular}

Fig. 1 A framework for proactive maintenance strategy selection

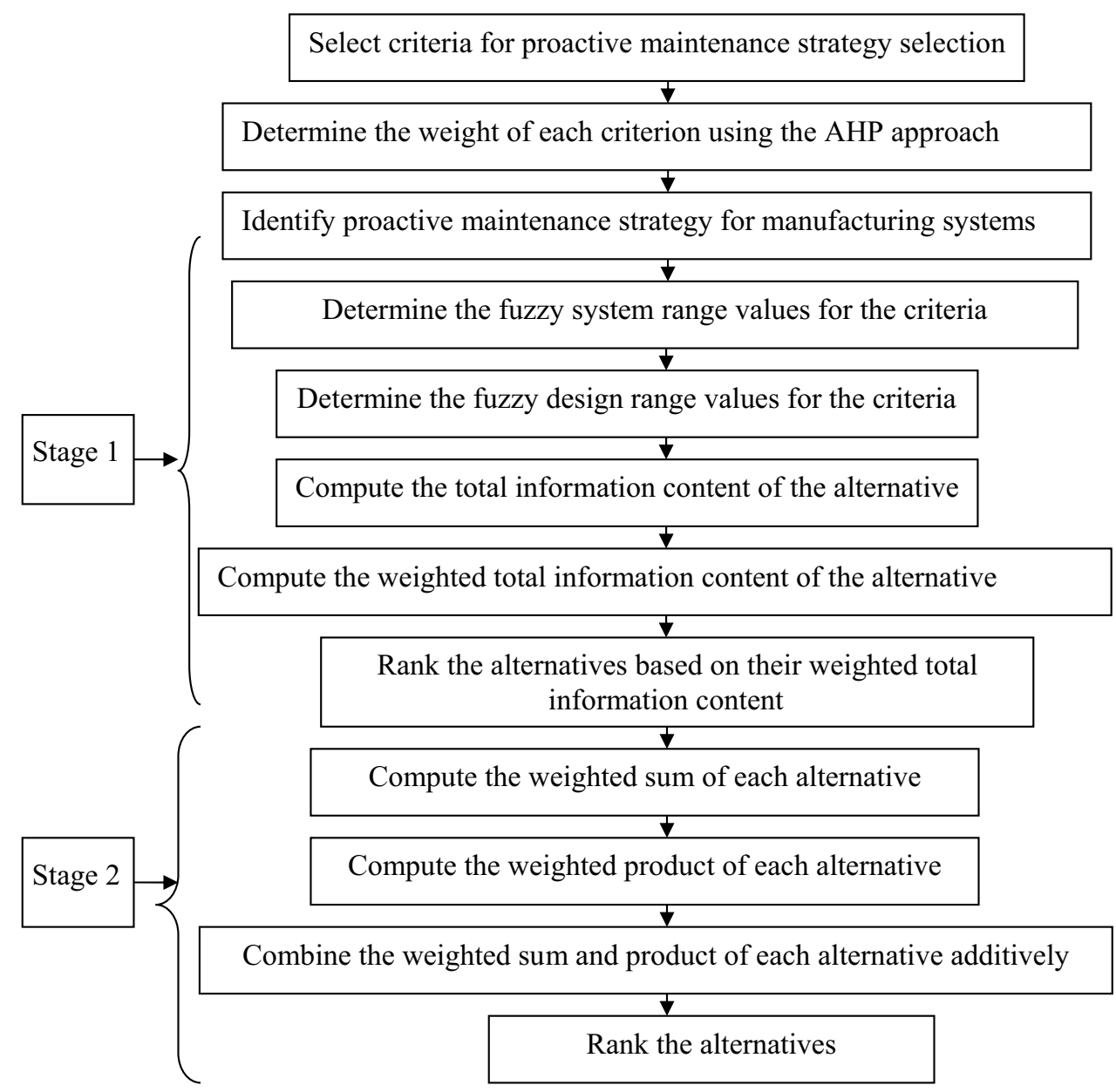

SN Applied Sciences 


\subsection{AHP}

The weights for the criteria which are used to select maintenance strategy are determined based on the AHP approach [42]. Production cost reduction $\left(G_{1}\right)$, reduced lead-time $\left(G_{2}\right)$, waste reduction $\left(G_{3}\right)$, profitability $\left(G_{4}\right)$ and production throughput $\left(\mathrm{G}_{5}\right)$ are considered as objectives of a manufacturing system. Five-scale importance intensity is used to determine the weights of the different criteria which are used for the maintenance strategy (Table 1).

\subsection{Axiomatic design principles}

A critical look at Table 1 showed that the relationships among the FRs and DRs for the various criteria are an uncoupled matrix (Eq. 1). This implies that the most suitable proactive maintenance strategy that will be selected for any manufacturing system based on the information in Table 1 will meet independence axiom [43].

$\left\{\begin{array}{l}F R_{1 j 1} \\ F R_{1 j 2} \\ F R_{1 j 3} \\ F R_{1 j 4}\end{array}\right\}=\left[\begin{array}{c}x 000 \\ 0 x 00 \\ 00 x 0 \\ 000 x\end{array}\right] *\left\{\begin{array}{l}D R_{1 j 1} \\ D R_{1 j 2} \\ D R_{1 j 3} \\ D R_{1 j 4}\end{array}\right\}$

The desire of decision-makers to express criteria values in linguistic terms introduces vagueness into multi-criteria analysis [44]. Due to vagueness in maintenance systems constraints, the current considered the use of membership functions (fuzzy logic) as a medium for the specification of the design ranges. The probability $\left(P_{i}\right)$ of satisfying $F R_{i}$ with $D R_{i}$, then the information concept is expressed as Eq. (2). The information content for each sub-criterion is determined (Eq. 3) to obtain the total information content for a criterion is expressed as Eq. (4). The weighted total information content $\left(I c_{l}\right)$ for a maintenance strategy is expressed as Eq. (5).

$I_{i}=\log _{2}\left(\frac{1}{p_{i}}\right)$

Table 1 Intensity of importance for weight determination

\begin{tabular}{ll}
\hline Definition & $\begin{array}{l}\text { Intensity of } \\
\text { importance }\end{array}$ \\
\hline Equal importance & 1 \\
Somewhat more important & 3 \\
Much more important & 5 \\
Very much more important & 7 \\
Absolutely more important & 9 \\
\hline
\end{tabular}

$$
I c_{i j}=\log _{2}\left(\frac{S A}{C R}\right)
$$

$I_{\text {total }, i}=\sum_{j=1}^{n} I c_{i j}$

$l c_{l}=\sum_{i=1}^{m} w_{i} \sum_{j=1}^{n} l c_{i j}$

where $S A$ is the system area, $C R$ is a common range, and $I c_{i j}$ is information content for criterion $i$ concerning subcriterion $j$ and $w_{i}$ represents weight criterion $i$.

The response of decision-makers' judgement that a proactive maintenance strategy will satisfy an FR with a DR is partitioned into a five-level scale (Table 2 and Fig. 2). The design range for all the FR is the same (Table 3 and Fig. 3).

Bojadziev and Bojadziev [45] reported that the crisp value for a TrFN could be determined using the values of $\tau_{1}$ and $\beta_{1}$ (Eq. 6). The CR and SA are determined based on Eq. (6).

$S A=\frac{1}{2}\left[\left(\tau_{1}+\beta_{1}\right)\right]$

Table 2 Linguistics variables and membership functions for system range

\begin{tabular}{lll}
\hline Linguistic variables & Abbreviations & Fuzzy number \\
\hline Very low & VL & $(0.0,0.1,0.2,0.3)$ \\
Low & L & $(0.2,0.3,0.4,0.5)$ \\
Fairly good & FG & $(0.4,0.5,0.6,0.7)$ \\
Good & G & $(0.6,0.7,0.8,0.9)$ \\
Very good & VG & $(0.8,0.9,1.0,1.0)$ \\
\hline
\end{tabular}

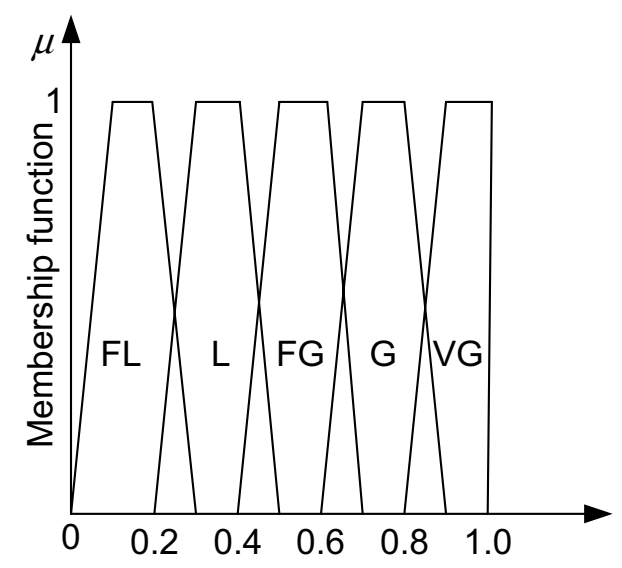

Fig. 2 Membership function for system range 
Table 3 Design range for proactive maintenance strategy selection

\begin{tabular}{ll}
\hline Criteria & Design range \\
\hline $\mathrm{FR}_{111}$ & $(0.25,0.5,0.75,1)$ \\
$\mathrm{FR}_{112}$ & $(0.25,0.5,0.75,1)$ \\
$\mathrm{FR}_{113}$ & $(0.25,0.5,0.75,1)$ \\
$\mathrm{FR}_{114}$ & $(0.25,0.5,0.75,1)$ \\
$\mathrm{FR}_{121}$ & $(0.25,0.5,0.75,1)$ \\
$\mathrm{FR}_{122}$ & $(0.25,0.5,0.75,1)$ \\
$\mathrm{FR}_{123}$ & $(0.25,0.5,0.75,1)$ \\
$\mathrm{FR}_{124}$ & $(0.25,0.5,0.75,1)$ \\
$\mathrm{FR}_{131}$ & $(0.25,0.5,0.75,1)$ \\
$\mathrm{FR}_{132}$ & $(0.25,0.5,0.75,1)$ \\
$\mathrm{FR}_{133}$ & $(0.25,0.5,0.75,1)$ \\
$\mathrm{FR}_{134}$ & $(0.25,0.5,0.75,1)$ \\
$\mathrm{FR}_{141}$ & $(0.25,0.5,0.75,1)$ \\
$\mathrm{FR}_{142}$ & $(0.25,0.5,0.75,1)$ \\
$\mathrm{FR}_{143}$ & $(0.25,0.5,0.75,1)$ \\
$\mathrm{FR}_{144}$ & $(0.25,0.5,0.75,1)$ \\
\hline
\end{tabular}

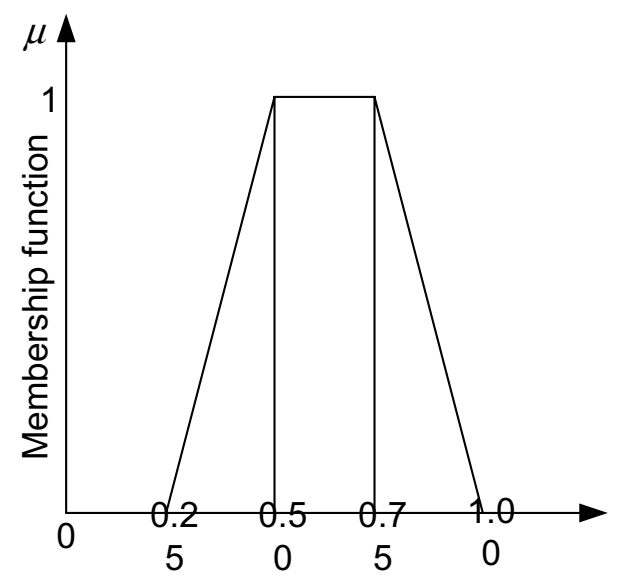

Fig. 3 Membership function for design range

The proposed framework depends on inputs from at least two decision-makers in a maintenance system. This implies that the responses from the decision-makers must be aggregated. Girubha and Vinodh [46] reported that for trapezoidal membership function, the aggregation of decision-makers responses is expressed as Eqs. (7) to (10).

$\alpha_{i j}=\min \left(\alpha_{i j k}\right)$

$\beta_{i j}=\frac{1}{K} \sum_{k=1}^{K} \beta_{i j k}$

$$
\begin{aligned}
& \tau_{i j}=\frac{1}{K} \sum_{k=1}^{K} \tau_{i j k} \\
& \delta_{i j}=\min \left(\delta_{i j k}\right)
\end{aligned}
$$

\subsection{Essentials of maintenance strategy}

\subsubsection{Justification for the multicriteria approach used}

In a manufacturing system, there exist different kinds of equipment and heavy components (production, pumps, rotary machinery, transformers, electric motors, circuit breakers, electrical equipment, batteries, valves, rolling bearings and heat exchangers). These types of equipment perform various functions and require different maintenance strategies, which are implemented by first establishing faults through diagnostic and troubleshooting techniques (e.g. vibration analysis and non-destructive testing) and then correcting these faults. A typical maintenance problem is to choose an appropriate maintenance strategy under uncertain conditions to revive equipment's health and enhance their performance and efficiency to their initial status.

The tradeoff between maintenance functional and design requirements, which include issues such as maintenance costs, key performance indices, maintenance resources and the work environment, brings about the difficulty in attaining successful maintenance strategy. Consequently, maintenance managers must consider the various functional and design factors using a multicriteria approach that has the potential to give more insights into the constituent factors of the functional and design issues concerned with the maintenance strategy selection. Using a multicriteria approach will confine the crucial highlights of a real-world maintenance management system. However, the dynamic nature of the maintenance environment, maintenance cost, workforce turnover, changing government policies affecting rolling mills operations and its maintenance practices has built-in an unavoidable uncertainty into the functional and design parameters of interest to this problem. This has nonetheless made the maintenance strategy selection more complex. Therefore, fuzzy logic theory embedded in fuzzy axiomatic design to develop an integrated model with analytical hierarchy process, and a selection of maintenance strategy in the manufacturing system through the weighted sum-product evaluation would be a competent multicriteria tool to aid maintenance decisions on the maintenance strategy problem. 


\subsubsection{The basis for the selection of variables}

This section provides the necessary basis to select the variables used in this work (Table 4 ). In aluminium rolling mills, the failures of equipment [47-49] (criterion $\mathrm{FR}_{122}$ ), for instance, aluminium circle blanking equipment, are a foremost hindrance to the rolling mill operations. When a breakdown occurs [50] (criteria $\mathrm{DR}_{131}, \mathrm{DR}_{121}, \mathrm{DR}_{122}$, $D_{123}, D_{124}$, and $D_{124}$ ), reinstating the equipment depends on the competence of the workforce [51, 52] (criterion $\mathrm{FR}_{143}$ ) and the maintenance resources $[53,54]$ (criteria $\mathrm{DR}_{111}, \mathrm{DR}_{112}, \mathrm{DR}_{113}, \mathrm{DR}_{114}$, and $\mathrm{FR}_{123}$ ) available to the maintenance team. Encouraging a philosophy of reliability (criterion $\mathrm{FR}_{134}$ ) among team members assists to establish the measures $[55,56]$, for instance, mean time to restore (criterion $\mathrm{FR}_{121}$ ), mean time between maintenance (criterion $\mathrm{FR}_{124}$ ), mean time between failures (criterion $\mathrm{FR}_{122}$ ), the number of defective products (criterion $\mathrm{DR}_{132}$ ), maintenance workforce cost (criterion $\mathrm{FR}_{111}$ ), spare parts cost $[53,54]$ (criterion $\mathrm{FR}_{112}$ ), overhead cost (criterion $\mathrm{FR}_{113}$ ), and consultancy cost (criterion $\mathrm{FR}_{114}$ ) are constantly tracked and enhanced while adopting the most appropriate maintenance strategy for the rolling mill plant $[53,54]$. Furthermore, the decision-maker needs to implement strategies to minimize maintenance time $[57,58]$ (criteria $\mathrm{DR}_{113}, \mathrm{DR}_{121}, \mathrm{DR}_{122}, \mathrm{DR}_{123}, \mathrm{DR}_{124}$, and $\mathrm{DR}_{133}$ ) and permit the plant to function at the uppermost efficiency (criterion $\mathrm{FR}_{123}$ ) that it can.

Besides, a programme of lean maintenance with a remedy to reduce waste in maintenance [56] (criteria $\mathrm{DR}_{111}, \mathrm{DR}_{112}, \mathrm{DR}_{113}$, and $\mathrm{DR}_{114}$ ) needs to be concurrently run with the choice of a maintenance strategy. However, the maintenance function ought to constantly assess human factors training (criterion $\mathrm{DR}_{143}$ ) to ascertain that it concentrates on actual life scenarios of human factors confrontations (criteria $\mathrm{FR}_{141}, \mathrm{FR}_{142}, \mathrm{FR}_{143}$, and $\mathrm{FR}_{144}$ ). Notwithstanding, the role of the maintenance function in the rolling mill should always be in focus. This role is to guarantee the complete availability of manufacturing equipment (criterion $\mathrm{FR}_{131}$ ), utilities, and associated facilities. This role should be performed at an optimal cost [56] (criteria $\mathrm{FR}_{111}, \mathrm{FR}_{112}, \mathrm{FR}_{113}$, and $\mathrm{FR}_{114}$ ) and under suitable states of quality (criteria $\mathrm{FR}_{132}$ and $\mathrm{DR}_{132}$ ), safety (criterion $\mathrm{DR}_{142}$ ) and perfection of the environment (criteria $\mathrm{DR}_{141}, \mathrm{DR}_{143}$ and $\left.\mathrm{DR}_{144}\right)$. Maintenance key performance indicators should always be in the focus of the maintenance team as it judges how well the functions in the rolling mill are being carried out regarding attaining maintenance objectives [56] (criteria $\mathrm{FR}_{121}, \mathrm{FR}_{122}, \mathrm{FR}_{123}$, and $\left.\mathrm{FR}_{124}\right)$, for instance, minimizing downtime $[57,58]$ (criteria $\mathrm{DR}_{134}$ and $\mathrm{DR}_{131}$ ) or cutting costs (criteria $\mathrm{FR}_{111}$, $F R_{112}, F R_{113}$, and $\left.F R_{114}\right)$. Furthermore, the enhancement

Table 4 Functional and design requirements

\begin{tabular}{|c|c|c|c|}
\hline \multicolumn{2}{|c|}{ Optimise maintenance system performance $\left(\mathrm{FR}_{1}\right)$} & \multicolumn{2}{|c|}{ Optimise maintenance system design $\left(\mathrm{DR}_{1}\right)$} \\
\hline \multirow[t]{4}{*}{$\begin{array}{l}\text { Minimise maintenance cost } \\
\quad\left(\mathrm{FR}_{11}\right)\end{array}$} & $\begin{array}{l}\text { Maintenance workforce cost } \\
\left(\mathrm{FR}_{111}\right)\end{array}$ & \multirow[t]{4}{*}{$\begin{array}{l}\text { Decrease maintenance resource } \\
\text { usage }\left(\mathrm{DR}_{11}\right)\end{array}$} & $\begin{array}{l}\text { Number of maintenance } \\
\text { workers }\left(\mathrm{DR}_{111}\right)\end{array}$ \\
\hline & Spare parts cost $\left(\mathrm{FR}_{112}\right)$ & & $\begin{array}{l}\text { Number of spare parts used } \\
\left(\mathrm{DR}_{112}\right)\end{array}$ \\
\hline & Overhead cost $\left(\mathrm{FR}_{113}\right)$ & & $\begin{array}{l}\text { Number of non-maintenance } \\
\text { workers }\left(\mathrm{DR}_{113}\right)\end{array}$ \\
\hline & Consultancy cost $\left(\mathrm{FR}_{114}\right)$ & & Number of consultations $\left(\mathrm{DR}_{114}\right)$ \\
\hline \multirow{4}{*}{$\begin{array}{l}\text { Optimise maintenance activities } \\
\left(\mathrm{FR}_{12}\right)\end{array}$} & Mean time to restore $\left(\mathrm{FR}_{121}\right)$ & \multirow{4}{*}{$\begin{array}{l}\text { Decrease amount of mainte- } \\
\text { nance time }\left(\mathrm{DR}_{12}\right)\end{array}$} & Amount of total repair time $\left(\mathrm{DR}_{121}\right)$ \\
\hline & $\begin{array}{l}\text { Mean time between failures } \\
\left(\mathrm{FR}_{122}\right)\end{array}$ & & Amount of operating time $\left(\mathrm{DR}_{122}\right)$ \\
\hline & Material usage $\left(\mathrm{FR}_{123}\right)$ & & Number of work orders $\left(\mathrm{DR}_{123}\right)$ \\
\hline & $\begin{array}{l}\text { Mean time between mainte- } \\
\text { nance }\left(\mathrm{FR}_{124}\right)\end{array}$ & & $\begin{array}{l}\text { Number of maintenance actions } \\
\left(\mathrm{DR}_{124}\right)\end{array}$ \\
\hline \multirow{4}{*}{$\begin{array}{l}\text { Optimise machine performance } \\
\left(\mathrm{FR}_{13}\right)\end{array}$} & Machine availability $\left(\mathrm{FR}_{131}\right)$ & \multirow{4}{*}{$\begin{array}{l}\text { Improve machine performance } \\
\left(\mathrm{DR}_{13}\right)\end{array}$} & Number of downtime $\left(\mathrm{DR}_{131}\right)$ \\
\hline & Product quality $\left(\mathrm{FR}_{132}\right)$ & & $\begin{array}{l}\text { Number of defective products } \\
\left(\mathrm{DR}_{132}\right)\end{array}$ \\
\hline & Machine efficiency $\left(\mathrm{FR}_{133}\right)$ & & Total inputs quantities $\left(\mathrm{DR}_{133}\right)$ \\
\hline & Machine reliability $\left(\mathrm{FR}_{134}\right)$ & & Failure rate $\left(\mathrm{DR}_{134}\right)$ \\
\hline \multirow{4}{*}{$\begin{array}{l}\text { Optimise human-factor perfor- } \\
\text { mance }\left(\mathrm{FR}_{14}\right)\end{array}$} & Motivation $\left(\mathrm{FR}_{141}\right)$ & \multirow{4}{*}{$\begin{array}{l}\text { Institute favourable working } \\
\text { environment }\left(\mathrm{DR}_{14}\right)\end{array}$} & Promotion rate $\left(\mathrm{DR}_{141}\right)$ \\
\hline & Workers safety $\left(\mathrm{FR}_{142}\right)$ & & $\begin{array}{l}\text { Number of accident prevention } \\
\left(\mathrm{DR}_{142}\right)\end{array}$ \\
\hline & Workers competence $\left(\mathrm{FR}_{143}\right)$ & & $\begin{array}{l}\text { Number of training programmes } \\
\left(\mathrm{DR}_{143}\right)\end{array}$ \\
\hline & Workers fatigue $\left(\mathrm{FR}_{144}\right)$ & & Amount of workloads $\left(\mathrm{DR}_{144}\right)$ \\
\hline
\end{tabular}


of reliability of the rolling mill may be attained by improving maintenance strategies.

2.3.2.1 The hierarchical framework of the model The directives for the hierarchical framework of the developed model are revealed in Figs. 4 and 5. Each of the models comprises of the three stages. The first stage for the functional requirements hierarchical framework (Fig. 4) symbolizes the general aim $\left(F R_{1}\right)$. The second stage signifies the principal objectives: $F R_{11}, F R_{12}, F R_{13}$ and $F R_{14}$. The third stage shows the options. Further, as revealed in Fig. 4 , the complete information relating to the number of options, four objectives and sixteen criteria id shown in the Sects. 2.3.3 to 2.3.18. Also, the first stage for the design requirement hierarchical structure (Fig. 5) represents the general aim $\left(D_{1}\right)$. The second stage reveals the chief objectives while the third stage shows the options. Further, as shown in Fig. 5, the total information regarding the number of options, four chief objectives, and sixteen criteria is shown in the Sects. 2.3.19 to 2.3.34.

2.3.2.2 Phase 1 (Aim) The aim of the functional requirement hierarchical framework aspect of the work is to optimise maintenance system performance $\left(\mathrm{FR}_{1}\right)$. By considering this aim, the appraisal and selection of the maintenance strategy were done based on the use of fuzzy logic theory embedded in fuzzy axiomatic design to develop an integrated model with analytic hierarchy process, and a selection of maintenance strategies in manufacturing systems through weighted sum-product evaluation. The aim of the design requirement hierarchical structure aspect of the research is to optimise maintenance system design $\left(D R_{1}\right)$. By considering this aim, the appraisal and selection of the maintenance strategy were done based on the use of the method discussed earlier.

2.3.2.3 Phase 2 (definition of objectives) The major elements here are the objectives. For the functional requirements, the objectives are: (1) Minimise maintenance cost $\left(F R_{11}\right)$, (2) Optimise maintenance activities $\left(F R_{12}\right)$, (3) Optimise machine performance $\left(\mathrm{FR}_{13}\right)$ and (4) Optimise human-factor performance $\left(\mathrm{FR}_{14}\right)$. For the design requirements, the four objectives are: (1) Decrease maintenance resource usage $\left(\mathrm{DR}_{11}\right)$, (2) Decrease amount of maintenance time $\left(D R_{12}\right)$, Improve machine performance $\left(D R_{13}\right)$, and Institute favourable working environment $\left(D_{14}\right)$

2.3.2.4 Phase 3 (set of criteria under consideration) By reflecting on the extant literature, the set of criteria (sixteen each for the functional requirements and design

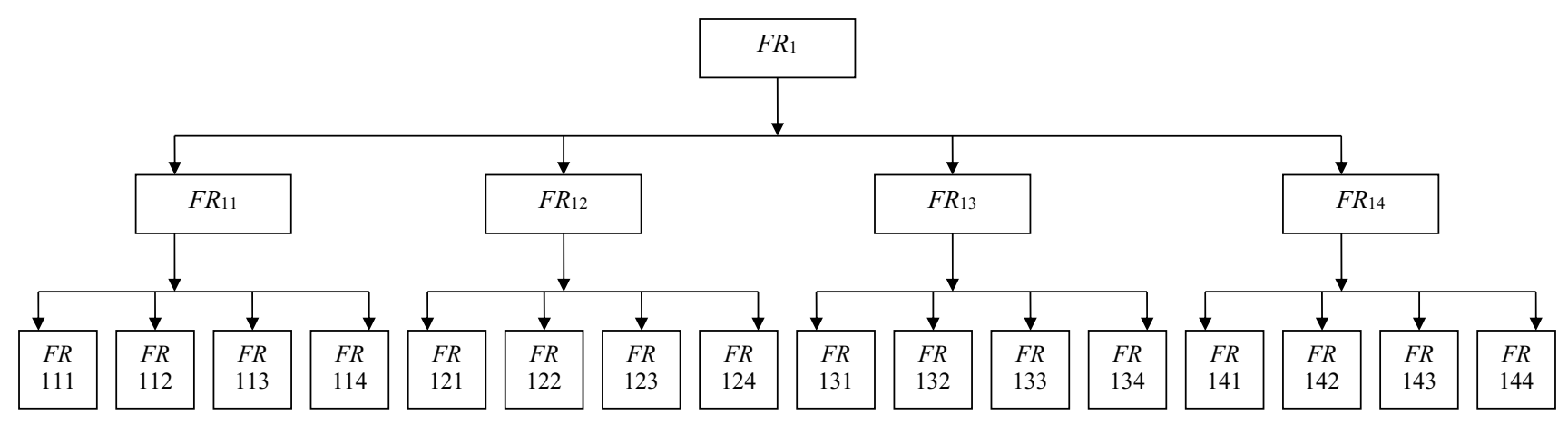

Fig. 4 Functional requirements hierarchical structure

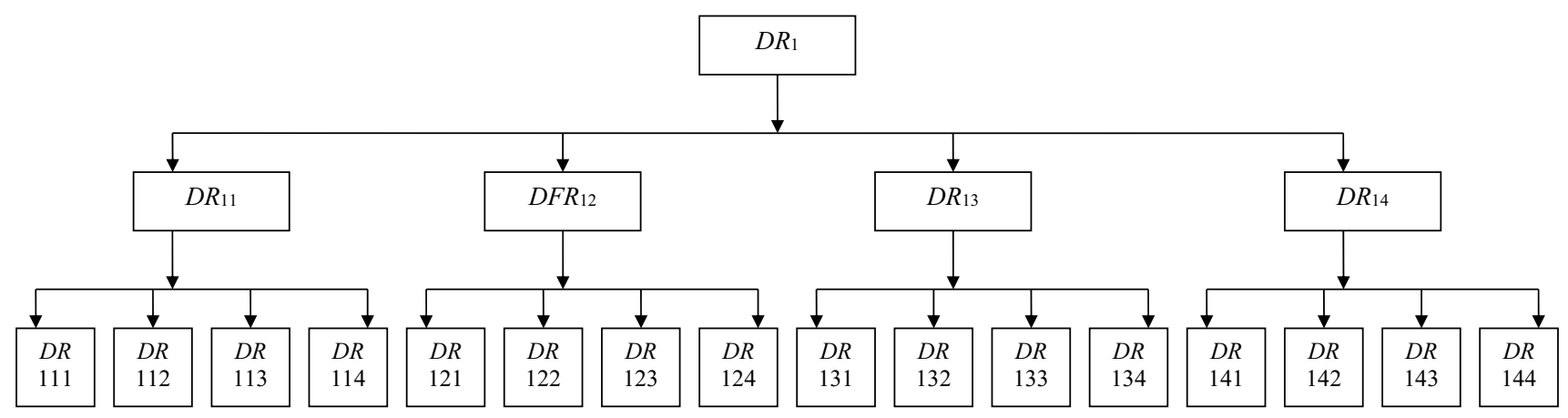

Fig. 5 Design requirements hierarchical structure 
requirements) are considered here (see Sect. 2.3.2) for this study towards the choice of the maintenance strategy for the rolling mill. As revealed in Figs. 4 and 5, the thirty-two criteria considered are discussed in Sects. 2.3.3 to 2.3.34.

\subsubsection{Maintenance workforce cost $\left(\mathrm{FR}_{111}\right)$}

While instituting maintenance strategies for manufacturing plants, determining the maintenance workforce cost is an important activity. In this aspect, the use of cost to establish trends is of great value. The cost of maintenance workforce is important because it has a deep influence on the efficiency of the workforce and the maintenance strategy that the rolling mill is capable to adopt. The workforce maintenance cost is substantially responsible for deciding on how much time the workforce would spend on preventive maintenance activities in comparison with the maintenance requirements of all the equipment.

\subsubsection{Spare parts cost $\left(\mathrm{FR}_{112}\right)$}

The cost of spare parts is a principal factor while deciding the appropriate maintenance strategy for attaining the goals of maintenance. The reason is that spare parts cost has a direct influence on attaining a high service level and make the implementation of maintenance strategy more effective and efficient $[53,54]$. The cost of spares is often minimal when the right maintenance strategy is implemented. However, with an unplanned breakdown, the unavailability of essential spare parts may lead to a very expensive factory shutdown.

\subsubsection{Overhead cost $\left(\mathrm{FR}_{113}\right)$}

The overhead cost in a rolling mill is a significant factor which should be considered while selecting a proper maintenance strategy. The reason is that expenses incurred in maintenance, if not properly controlled reduces the profit and may threaten the existence of the plant. Consequently, cost-cutting drives such as lean maintenance is an important phenomenon to consider in this instance. Major success in the cost-cutting effort of the maintenance function may be achieved by waste reduction on major utilities used in the rolling mills, including gas, sewer, electricity and phone expenses.

\subsubsection{Consultancy cost $\left(\mathrm{FR}_{114}\right)$}

In the process of choosing maintenance strategies for a manufacturing system, there is scope to integrate consultancy cost. However, efforts should be made to minimise this factor for a successful implementation of maintenance strategy in a rolling plant. An avenue to reducing cost is the avoidance of inviting the consultants to be physically present in the company. Rather, the instruction may be received from the consultants while fine-tuning of the solution to the problem could be made through communication methods such as exchanges of electronic mails, Fax services and telephone services. This option is cheaper and saves cost.

\subsubsection{Mean time to restore $\left(\mathrm{FR}_{121}\right)$}

Mean time to restore is an imperative factor that should be considered when deciding on the choice of maintenance strategy in a rolling mill. The production manager is eager to know when the production line will be restored as the downtime has caused production losses and idleness of production staff. Moreover, it is expected that the equipment should be restored to the as-good-as-new state.

\subsubsection{Mean time between failures $\left(\mathrm{FR}_{122}\right)$}

Frequent production interruptions directly or indirectly affect every worker in the rolling mill; the production workers are idler, the integrity of repairs is questioned by the production team. The justification for spare replacement of the broken part(s) during the last maintenance exercise is questioned. The customer is anxious to receive the ordered good already paid for. Hence, while choosing the maintenance strategy for the rolling mill, it is extremely critical to deliberate on the mean time between failures of the machines. Moreover, this criterion evaluates the competence of the maintenance team, skills, availability of repair resources and response period of the maintenance team to maintenance failures.

\subsubsection{Material usage $\left(\mathrm{FR}_{123}\right)$}

Industries in general monitor material usage to determine the impact of the negligence of both production and maintenance workers on the usage. They also determine the effects of untrained staff, the use of sub-standard materials and the inadequate state of the equipment on the usage. All these help them in establishing measures against excessive material usage. But it is essential to consider material usage when choosing a maintenance strategy for the rolling mill. Moreover, deep insight on material and its relationship with the maintenance process is a necessary viewpoint that any maintenance engineer or manager should possess for success in the implementation of a good maintenance strategy. Besides, it is advisable for senior maintenance personnel in the organization to go and see the actual manufacturing procedures of the material being supplied to his/her company, to observe how the materials are being manufactured. This brings about 
a deeper understanding of the materials. Furthermore, understanding the properties of the materials in terms of physical, chemical and mechanical characteristics is of great values to the maintenance engineer.

\subsubsection{Mean time between maintenance $\left(\mathrm{FR}_{124}\right)$}

Mean time between maintenance differs from mean time between failures in that the earlier involves preventive maintenance activities, which forces the machines to be maintained at predetermined periods. This metric is an essential factor that needs to be considered while choosing the maintenance strategy for the rolling mill. Moreover, this is a metric used by the maintenance manager to evaluate the performance of the rolling mills. Furthermore, it accounts for the timeframe between the implementation of maintenance activity and the other. Finally, the maintenance engineer uses them to monitor the performance of the crew as well as to judge whether the ageing effects of the machines are having impacts on their availability for productive usage.

\subsubsection{Machine availability $\left(\mathrm{FR}_{131}\right)$}

For the rolling mill, the consideration of machine availability is essential. Thus, the incorporation of machine availability as a factor in the selection of maintenance strategy for a rolling mill is a worthwhile decision. Moreover, the availability of machines is a good metric to determine the level of satisfaction of the customer as continuous production guarantees that customers' order will be supplied on time.

\subsubsection{Product quality $\left(\mathrm{FR}_{132}\right)$}

To guarantee continuous patronage of the company's product, high-quality products are essential. Thus it is extremely crucial to consider product quality when choosing the maintenance strategy for the rolling mill. Moreover, rolling mills products need to be of acceptable quality, incorporating the perceived beneficial characteristics of the customer into the product, and these characteristics are specified by the customer. Furthermore, deviations from the standard often attract penalties, and the severity of penalties depends on the extent of deviation of the product characteristics from standard and the impact of such product failures on the business of the customer.

\subsubsection{Machine efficiency $\left(\mathrm{FR}_{133}\right)$}

A necessary level of machine efficiency for the diverse machines of the rolling mill is essential at the operational stage of a rolling mill so that funds will be conserved. Thus, it is essential to consider machine efficiency as a factor when deciding on the choice of maintenance strategy for the rolling mill.

\subsubsection{Machine reliability $\left(\mathrm{FR}_{134}\right)$}

The failure rate of the equipment, which determines its ability to execute its anticipated task, varies from equipment to the other. Even for a section of the rolling mill to another section, the machine reliability varies. In general, it is known that a machine cannot be reliable when it has broken down. Consequently, it is extremely critical to consider machine reliability when choosing a maintenance strategy for the rolling mill.

\subsubsection{Motivation $\left(\mathrm{FR}_{141}\right)$}

The motivation of a rolling mill worker is described as the degree of energy, demonstrated in the worker's commitment to the plant. It is also a measure of the rolling mill worker's creative attributes on the job. However, motivation is one of the most significant factors to incorporate when considering the choice of maintenance strategy in a rolling mill.

\subsubsection{Workers safety $\left(\mathrm{FR}_{142}\right)$}

In a rolling mill, safety refers to making the work environment safe. The equipment should operate in a risk-free condition and all the procedures to ascertain safety is in place should be adhered to strictly by all the workers and stakeholders in the factory. Hazards should be eliminated and the threats reduced with adequate safety training. However, with inadequate safety measures, the rolling mill places its workers in danger and the reputation of the products as well as revenues are in great danger. It is very important to incorporate this factor into the framework of analysis when considering the choice of maintenance strategy for a rolling mill.

\subsubsection{Workers' competence $\left(\mathrm{FR}_{143}\right)$}

The competence of a worker is the skill set and actions applied to the job that the worker is engaged for. It is a guideline to establish the expectations from the technical maintenance worker in a rolling mill and also weighed against the culture obtainable in the rolling mill. This parameter should be used as a yardstick when analysing the choice of maintenance strategy for a rolling mill. 


\subsubsection{Workers fatigue $\left(\mathrm{FR}_{144}\right)$}

Regarding the fatigue of workers in a rolling mill, a clear understanding of this phenomenon is essential since workers will normally run shift duties for one another. Therefore, it is essential to consider this factor when choosing maintenance strategies for a rolling mill. Furthermore, the worker risks injuries when fatigue is experienced and the safety performance of the worker drops.

\subsubsection{Number of maintenance workers $\left(D_{111}\right)$}

The repair workers are engaged in a wide variety of tasks in the rolling mills, including electrical repairs, plumbing, repair of air conditioning and heating systems, floor repairs and painting. The number of maintenance workers required in one rolling mill differs from the other since the capacity of the plants varies. This, this factor, i.e. the number of maintenance workers has become a most essential one to consider while selecting maintenance strategy for the rolling mill.

\subsubsection{Number of spare parts used $\left(\mathrm{DR}_{112}\right)$}

The spare parts needed in a rolling mill could be consumables or repairable. In the present-day situation where it is increasingly difficult to have storage space, the factor i.e. number of spare parts becomes an essential one to consider in the choice of maintenance strategy for a rolling mill. Moreover, this factor is necessary to determine the number of workers to engage in the stores' department of the rolling mill that will be responsible for the safeguard of the spares.

\subsubsection{Number of non-maintenance workers $\left(D_{113}\right)$}

Non-maintenance workers often work with the technically-oriented repair workers on projects in the rolling mill. However, it is essential to incorporate this factor i.e. number of non-maintenance workers when considering the choice of maintenance strategy in a rolling mill.

\subsubsection{Number of consultation $\left(D_{114}\right)$}

In the rolling mill, consultations are required to solve technically complex maintenance problems. A case is the introduction of new technology to produce coils, in which the machine ceases to function despite following the specified guidelines for operation in the manuals. Consultations are needed to solve this problem. Thus, it is necessary to incorporate this factor i.e. number of consultations when considering the maintenance strategy selection in a rolling mill.

\subsubsection{Amount of total repair time $\left(\mathrm{DR}_{121}\right)$}

The sum of repair time is necessary to restore a failed component is an essential metric of maintenance performance. However, for a large plant as a rolling mill with many equipment and sub-equipment, analyzing this could be cumbersome. But understanding this is essential for progress in the maintenance of the rolling mill. Therefore, the incorporation of this factor i.e. the amount of total repair time when considering the selection of maintenance strategy for a rolling mill is important.

\subsubsection{Amount of operating time $\left(D_{122}\right)$}

The time standard used to carry out maintenance tasks varies and also varies for equipment. But this factor, i.e. amount of operating time, need to be considered when selecting maintenance strategy for a rolling mill. Moreover, there is a necessity to control it so that resources may be conserved.

\subsubsection{Number of work orders $\left(D_{123}\right)$}

Often, a machine operator submits a work request as the equipment malfunctions. Based on a review by the maintenance manager, some additional information may be included. Such information is the schedule for the task and the assignment of the job to a technician. This document becomes a work order. However, the number of work orders varies from one organization to another and within the equipment units. Thus, the number of the work order is one of the very important factors to be included in choosing the maintenance strategy for the rolling mill.

\subsubsection{Number of maintenance actions $\left(D^{124}\right)$}

In restoring failed equipment or retaining a functional facility, steps are taken to ensure that the system works according to the operating conditions. Furthermore, the aim is to attain the utmost useful life of the equipment. However, maintenance actions should be regulated. Thus, the number of maintenance actions becomes an important factor when choosing the maintenance strategy for the rolling mill.

\subsubsection{Number of downtime $\left(\mathrm{DR}_{131}\right)$}

In rolling mills, downtime impacts on operations drag productivity and profit. However, it is important to incorporate 
this factor, i.e. number of downtime when considering the maintenance strategy for the rolling mill.

\subsubsection{Number of defective products $\left(\mathrm{DR}_{132}\right)$}

Defective products from a rolling mill are poor quality outputs that degrade the image of the company. Defective products are many times linked to inadequate maintenance activities on machines. It is generally known that everybody dislikes defective products and efforts are made by the rolling mill workers to reduce the quantity and rate at which defective products are produced from their machines. This factor is very essential to be incorporated into the framework for analysing the choice of maintenance strategy in a rolling mill.

\subsubsection{Total inputs quantities $\left(\mathrm{DR}_{133}\right)$}

In a production system, inputs, output and the transformation process are the important elements that judge the effectiveness of the system. However, the total input quantities used for production is very important and it is often associated with machine usage, which translates into the likelihood of a machine breaking down early if more material inputs are used than the capacity of the machine. Consequently, the total input quantities become an important factor when choosing the maintenance strategy for the rolling mill.

\subsubsection{Failure rate $\left(D_{134}\right)$}

Rolling mills equipment fails at different frequencies, and this is captured as the failure rate of the equipment. Historical data on failure rate serves as information for the maintenance manager to do the actual future prediction of the pattern of failure frequency. Such information helps to plan for materials and human resources as well as the maintenance strategy to adopt to combat such failures. Failure data collected over a long period serves also as essential information to establish adequate equipment management and the analysis of equipment lifecycle. Thus, the failure rate factor becomes a significant factor when choosing the maintenance strategy for the rolling mill.

\subsubsection{Promotion rate $\left(\mathrm{DR}_{141}\right)$}

Promotion entails the relocation of a rolling mill worker to a different rank, implying elevated benefits, wage, or rank weighed against the previous rank. However, of more interest to the rolling mill worker is the promotion rate, which is regarded as a work environmental factor that may stimulate retention of the worker on the job or his/ her turnover. The promotion rate defines the ratio of the sum of promotions in an assessment period (usually for 12 months) to the number of workers in the rolling mill. Thus, the promotion rate becomes an important factor when choosing the maintenance strategy for the rolling mill.

\subsubsection{Number of accident prevention $\left(\mathrm{DR}_{142}\right)$}

An accident is a mishap that may lead to injury, loss of parts of the body or loss of lives. A favourable work environment is one such that the number of accidents that occur in a planned period is minimized. Human factors play a significant role in controlling the number of accidents and this could be closely associated with the selection of maintenance strategy. Accident prevention is the central activity of many organizations that invests in safety. This factor is very essential to be incorporated into the framework for analysing the choice of maintenance strategy in a rolling mill.

\subsubsection{Number of training programmes $\left(\mathrm{DR}_{143}\right)$}

Training refers to a worker's development through new skill acquisition and knowledge attainment to enhance the competence of the worker on the job. This could be an onthe-job training or off-the-job training programme. Technical and non-technical training programmes are essential for all cadres of rolling mills workers. However, assuming there is standardization in the training programme such that all training programmes meet the training needs of the worker, the issue now is how many of these training programmes would aid in achieving effective maintenance strategy deployment of the rolling mill. This factor is very essential to be incorporated into the framework for analysing the choice of maintenance strategy in a rolling mill.

\subsubsection{Amount of workloads $\left(\mathrm{DR}_{144}\right)$}

Maintenance workers vary in degrees of responsibilities and the level of administrative and technical contents of the jobs. Though the manager in the rolling mill engages in more administrative tasks than lower-level workers, the workload may be the same for two workers at different levels; this is in terms of what to do. However, it is difficult to evaluate this. Workload refers to the amount of work the rolling mill workers have to do. This is often viewed from how difficult the duties to be accomplished are and the actual amount to do. The workload is linked to maintenance strategy for effective goal attainment. Consequently, the amount of workloads becomes an important factor when choosing the maintenance strategy for the rolling mill. 


\subsection{WASPAS}

Over the years, the use of WASPAS approach for the selection of alternative to be used as a solution to a problem is gaining more attention among researchers and industrial practitioners across the globe $[59,60]$. The wide application of WASPAS is due to its ease of usage and quality solution generation. The basic stages for WASPAS implementation are as follows $[59,60]$ :

Stage 1: Determination of the relative importance of maintenance strategy

The relative importance of each maintenance strategy is determined using the weighted sum method (Eq. 11) and weighted product method (Eq. 12).

$$
\begin{aligned}
& Q_{l}^{(1)}=\sum_{i=1}^{m} \bar{x}_{i l} \cdot w_{i} \\
& Q_{l}^{(2)}=\prod_{l=1}^{m} \bar{x}_{i l}^{w_{l}}
\end{aligned}
$$

where $w_{i}$ is the weight for criterion $l$.

Stage 2: Ranking of maintenance strategy

This stage entails the aggregation of weight sum and weighted product methods results additively (Eq. 13) using a constant parameter $(\lambda)$.

$Q_{l}=\lambda Q_{1}^{1}+(1-\lambda) Q_{l}^{2}$

where $\lambda=0,0.1, \ldots, 1$; and $Q$, represents the WASPAS value for proactive maintenance strategy $I$.

\section{Case study}

The studied factory is a large rolling mill in Nigeria. The factory has different cadres of personnel, including artisans, technicians, engineers, managers and senior managers in maintenance. The major equipment in the plant includes continuous casting machine, overhead crane, cold shearing, rotary shearing machines (billet shearing, rotary shearing machines), pre-heating furnace, induction furnace, heavy capacity, pinion gearboxes, hydraulic power packs, mill strands, controlled lifting table, conveyor roller tables, compressors (single-phase double performing and double-phase single performing), water pumps. The input parameters were selected as they seem to reveal the most or the least important maintenance strategy for the rolling mill. The selection of a proactive maintenance strategy for a roll milling factory was used to verify the application of the proposed conceptual framework. Three decision-makers were considered during the framework application. The total number of manufacturing goals was five, while the total number of maintenance criteria was four. Linguistics responses from the decision-makers were converted to crisp values using trapezoidal membership function. The importance of the maintenance criteria was determined for three decision-makers (Table 5). Similarly, the importance of the manufacturing goals was also determined for three decision-makers (Table 6).

Based on the decision-makers responses, the second and third decision-maker's responses showed that the most important manufacturing goal was $\mathrm{G}_{1}$ (Production cost). The first decision-maker's responses indicated the least important manufacturing goal $\mathrm{G}_{5}$ (production throughput), while the most important manufacturing goal was (profitability). The second decision-maker believed that $\mathrm{G}_{3}$ (waste reduction) was the least important manufacturing goal. The last decision-maker believed that $G_{3}$ and $G_{5}$ are the least important manufacturing
Table 5 Importance of maintenance criteria

\begin{tabular}{lllllll}
\hline $\begin{array}{l}\text { Decision- } \\
\text { makers }\end{array}$ & Criteria & $\mathrm{G}_{1}$ & $\mathrm{G}_{2}$ & $\mathrm{G}_{3}$ & $\mathrm{G}_{4}$ & $\mathrm{G}_{5}$ \\
\hline $\mathrm{D}_{1}$ & $\mathrm{C}_{1}$ & 0.4836 & 0.1007 & 0.4534 & 0.1901 & 0.0740 \\
& $\mathrm{C}_{2}$ & 0.2424 & 0.4868 & 0.1660 & 0.1901 & 0.5678 \\
& $\mathrm{C}_{3}$ & 0.2424 & 0.3863 & 0.2091 & 0.3802 & 0.2841 \\
& $\mathrm{C}_{4}$ & 0.0317 & 0.0262 & 0.1715 & 0.2396 & 0.0741 \\
$\mathrm{D}_{2}$ & $\mathrm{C}_{1}$ & 0.2043 & 0.0473 & 0.5973 & 0.0520 & 0.3064 \\
& $\mathrm{C}_{2}$ & 0.0067 & 0.2286 & 0.1236 & 0.3967 & 0.3461 \\
& $\mathrm{C}_{3}$ & 0.2491 & 0.1814 & 0.1396 & 0.4480 & 0.3069 \\
& $\mathrm{C}_{4}$ & 0.5399 & 0.5427 & 0.1396 & 0.1033 & 0.0406 \\
$\mathrm{D}_{3}$ & $\mathrm{C}_{1}$ & 0.2043 & 0.3288 & 0.2212 & 0.4369 & 0.0147 \\
& $\mathrm{C}_{2}$ & 0.0067 & 0.1712 & 0.2212 & 0.1599 & 0.5410 \\
& $\mathrm{C}_{3}$ & 0.2491 & 0.3288 & 0.2788 & 0.3198 & 0.4295 \\
& $\mathrm{C}_{4}$ & 0.5399 & 0.1712 & 0.2788 & 0.0833 & 0.0148 \\
\hline
\end{tabular}


Table 6 Importance of manufacturing goals

\begin{tabular}{llll}
\hline Goals & $D_{1}$ & $D_{2}$ & $D_{3}$ \\
\hline$G_{1}$ & 0.3175 & 0.5852 & 0.5852 \\
$G_{2}$ & 0.0976 & 0.1331 & 0.1331 \\
$G_{3}$ & 0.0976 & 0.0154 & 0.0154 \\
$G_{4}$ & 0.4618 & 0.1484 & 0.2508 \\
$G_{5}$ & 0.0254 & 0.1179 & 0.0154 \\
\hline
\end{tabular}

Table 7 Criteria weights

\begin{tabular}{lllll}
\hline Criteria & $D_{1}$ & $D_{2}$ & $D_{3}$ & Average weight \\
\hline$C_{1}$ & 0.2973 & 0.1789 & 0.2765 & 0.2509 \\
$C_{2}$ & 0.2429 & 0.1359 & 0.0786 & 0.1525 \\
$C_{3}$ & 0.3179 & 0.2747 & 0.2798 & 0.2908 \\
$C_{4}$ & 0.1465 & 0.4105 & 0.3642 & 0.3071 \\
\hline
\end{tabular}

goals (Table 6). The average values of the decision-makers manufacturing goals importance showed that $\mathrm{G}_{3}$ was the least important manufacturing goal (Table 6 ).

The weights for the maintenance criteria (Table 7) were obtained by considering the information in Tables 5 and 6 . The weights for the maintenance criteria that were used for the analysis were taken as the average weights from the three decision-makers (Table 7). The most important maintenance criterion for the case study was $C_{4}$ (humanfactor), while $C_{2}$ (maintenance activities) was the least important maintenance criterion (Table 7).

Based on the linguistic information obtained from three decision-makers $\left(D_{k}\right)$, the information in Tables 1 and 2 was used to determine the crisp functional requirements values for the different proactive maintenance strategies (Tables 8, 9, 10 and 11).

The trapezoidal fuzzy numbers for the system range (Table 12) were obtained using the information presented in Tables 8, 9, 10 and 11. This was achieved based on the expressions in Eqs. (8) to (11).

The crisp values for the different functional requirements for the case study were determined using Eq. (7) for
Table 8 Importance of subcriteria concerning $\mathrm{FR}_{11}$

\begin{tabular}{lllll}
\hline & $\mathrm{FR}_{111}$ & $\mathrm{FR}_{112}$ & $\mathrm{FR}_{113}$ & $\mathrm{FR}_{114}$ \\
\hline$D_{1}$ & & & & \\
$\mathrm{~A}_{1}$ & $(0.6,0.7,0.8,0.9)$ & $(0.6,0.7,0.8,0.9)$ & $(0.4,0.5,0.6,0.7)$ & $(0.6,0.7,0.8,0.9)$ \\
$\mathrm{A}_{2}$ & $(0.6,0.7,0.8,0.9)$ & $(0.4,0.5,0.6,0.7)$ & $(0.6,0.7,0.8,0.9)$ & $(0.4,0.5,0.6,0.7)$ \\
$\mathrm{A}_{3}$ & $(0.2,0.3,0.4,0.5)$ & $(0.4,0.5,0.6,0.7)$ & $(0.2,0.3,0.4,0.5)$ & $(0.2,0.3,0.4,0.5)$ \\
$D_{2}$ & & & & \\
$\mathrm{~A}_{1}$ & $(0.6,0.7,0.8,0.9)$ & $(0.6,0.7,0.8,0.9)$ & $(0.6,0.7,0.8,0.9)$ & $(0.6,0.7,0.8,0.9)$ \\
$\mathrm{A}_{2}$ & $(0.6,0.7,0.8,0.9)$ & $(0.8,0.9,1.0,1.0)$ & $(0.6,0.7,0.8,0.9)$ & $(0.8,0.9,1.0,1.0)$ \\
$\mathrm{A}_{3}$ & $(0.6,0.7,0.8,0.9)$ & $(0.6,0.7,0.8,0.9)$ & $(0.6,0.7,0.8,0.9)$ & $(0.6,0.7,0.8,0.9)$ \\
$D_{3}$ & & & & \\
$\mathrm{~A}_{1}$ & $(0.6,0.7,0.8,0.9)$ & $(0.4,0.5,0.6,0.7)$ & $(0.4,0.5,0.6,0.7)$ & $(0.2,0.3,0.4,0.5)$ \\
$\mathrm{A}_{2}$ & $(0.4,0.5,0.6,0.7)$ & $(0.6,0.7,0.8,0.9)$ & $(0.4,0.5,0.6,0.7)$ & $(0.6,0.7,0.8,0.9)$ \\
$\mathrm{A}_{3}$ & $(0.6,0.7,0.8,0.9)$ & $(0.8,0.9,1.0,1.0)$ & $(0.6,0.7,0.8,0.9)$ & $(0.6,0.7,0.8,0.9)$ \\
\hline
\end{tabular}

\begin{tabular}{lllll}
\hline & $\mathrm{FR}_{121}$ & $\mathrm{FR}_{122}$ & $\mathrm{FR}_{123}$ & $\mathrm{FR}_{124}$ \\
\hline$D_{1}$ & & & \\
$\mathrm{~A}_{1}$ & $(0.4,0.5,0.6,0.7)$ & $(0.6,0.7,0.8,0.9)$ & $(0.4,0.5,0.6,0.7)$ & $(0.6,0.7,0.8,0.9)$ \\
$\mathrm{A}_{2}$ & $(0.4,0.5,0.6,0.7)$ & $(0.2,0.3,0.4,0.5)$ & $(0.4,0.5,0.6,0.7)$ & $(0.6,0.7,0.8,0.9)$ \\
$\mathrm{A}_{3}$ & $(0.4,0.5,0.6,0.7)$ & $(0.2,0.3,0.4,0.5)$ & $(0.4,0.5,0.6,0.7)$ & $(0.6,0.7,0.8,0.9)$ \\
$D_{2}$ & & & & \\
$\mathrm{~A}_{1}$ & $(0.6,0.7,0.8,0.9)$ & $(0.6,0.7,0.8,0.9)$ & $(0.8,0.9,1.0,1.0)$ & $(0.8,0.9,1.0,1.0)$ \\
$\mathrm{A}_{2}$ & $(0.8,0.9,1.0,1.0)$ & $(0.8,0.9,1.0,1.0)$ & $(0.6,0.7,0.8,0.9)$ & $(0.6,0.7,0.8,0.9)$ \\
$\mathrm{A}_{3}$ & $(0.6,0.7,0.8,0.9)$ & $(0.8,0.9,1.0,1.0)$ & $(0.6,0.7,0.8,0.9)$ & $(0.6,0.7,0.8,0.9)$ \\
$D_{3}$ & & & & \\
$\mathrm{~A}_{1}$ & $(0.6,0.7,0.8,0.9)$ & $(0.8,0.9,1.0,1.0)$ & $(0.8,0.9,1.0,1.0)$ & $(0.4,0.5,0.6,0.7)$ \\
$\mathrm{A}_{2}$ & $(0.4,0.5,0.6,0.7)$ & $(0.6,0.7,0.8,0.9)$ & $(0.8,0.9,1.0,1.0)$ & $(0.6,0.7,0.8,0.9)$ \\
$\mathrm{A}_{3}$ & $(0.4,0.5,0.6,0.7)$ & $(0.2,0.3,0.4,0.5)$ & $(0.4,0.5,0.6,0.7)$ & $(0.6,0.7,0.8,0.9)$ \\
\hline
\end{tabular}

Table 9 Importance of subcriteria concerning $\mathrm{FR}_{12}$ 
Table 10 Importance of subcriteria concerning $\mathrm{FR}_{13}$

\begin{tabular}{lllll}
\hline & $\mathrm{FR}_{131}$ & $\mathrm{FR}_{132}$ & $\mathrm{FR}_{133}$ & $\mathrm{FR}_{134}$ \\
\hline$D_{1}$ & & & & \\
$\mathrm{~A}_{1}$ & $(0.4,0.5,0.6,0.7)$ & $(0.4,0.5,0.6,0.7)$ & $(0.6,0.7,0.8,0.9)$ & $(0.4,0.5,0.6,0.7)$ \\
$\mathrm{A}_{2}$ & $(0.6,0.7,0.8,0.9)$ & $(0.6,0.7,0.8,0.9)$ & $(0.6,0.7,0.8,0.9)$ & $(0.6,0.7,0.8,0.9)$ \\
$\mathrm{A}_{3}$ & $(0.4,0.5,0.6,0.7)$ & $(0.4,0.5,0.6,0.7)$ & $(0.4,0.5,0.6,0.7)$ & $(0.6,0.7,0.8,0.9)$ \\
$D_{2}$ & & & & \\
$\mathrm{~A}_{1}$ & $(0.8,0.9,1.0,1.0)$ & $(0.8,0.9,1.0,1.0)$ & $(0.8,0.9,1.0,1.0)$ & $(0.8,0.9,1.0,1.0)$ \\
$\mathrm{A}_{2}$ & $(0.6,0.7,0.8,0.9$ & $(0.4,0.5,0.6,0.7)$ & $(0.6,0.7,0.8,0.9)$ & $(0.6,0.7,0.8,0.9)$ \\
$\mathrm{A}_{3}$ & $(0.8,0.9,1.0,1.0)$ & $(0.8,0.9,1.0,1.0)$ & $(0.6,0.7,0.8,0.9)$ & $(0.6,0.7,0.8,0.9)$ \\
$D_{3}$ & & & & \\
$\mathrm{~A}_{1}$ & $(0.6,0.7,0.8,0.9)$ & $(0.4,0.5,0.6,0.7)$ & $(0.6,0.7,0.8,0.9)$ & $(0.8,0.9,1.0,1.0)$ \\
$\mathrm{A}_{2}$ & $(0.4,0.5,0.6,0.7)$ & $(0.2,0.3,0.4,0.5)$ & $(0.8,0.9,1,1)$ & $(0.6,0.7,0.8,0.9)$ \\
$\mathrm{A}_{3}$ & $(0.4,0.5,0.6,0.7)$ & $(0.6,0.7,0.8,0.9)$ & $(0.4,0.5,0.6,0.7)$ & $(0.4,0.5,0.6,0.7)$ \\
\hline
\end{tabular}

Table 11 Importance of subcriteria concerning $\mathrm{FR}_{14}$

\begin{tabular}{lllll}
\hline & $\mathrm{FR}_{141}$ & $\mathrm{FR}_{142}$ & $\mathrm{FR}_{143}$ & $\mathrm{FR}_{144}$ \\
\hline$D$ & & & & \\
$\mathrm{~A}_{1}$ & $(0.6,0.7,0.8,0.9)$ & $(0.6,0.7,0.8,0.9)$ & $(0.4,0.5,0.6,0.7)$ & $(0.4,0.5,0.6,0.7)$ \\
$\mathrm{A}_{2}$ & $(0.4,0.50 .6,0.7)$ & $(0.6,0.70 .8,0.9)$ & $(0.4,0.5,0.6,0.7)$ & $(0.4,0.5,0.6,0.7)$ \\
$\mathrm{A}_{3}$ & $(0.2,0.3,0.4,0.5)$ & $(0.4,0.5,0.6,0.7)$ & $(0.4,0.5,0.6,0.7)$ & $(0.4,0.5,0.6,0.7)$ \\
$D 2$ & & & & \\
$\mathrm{~A}_{1}$ & $(0.4,0.5,0.6,0.7)$ & $(0.8,0.9,1.0,1.0)$ & $(0.6,0.7,0.8,0.9)$ & $(0.4,0.5,0.6,0.7)$ \\
$\mathrm{A}_{2}$ & $(0.6,0.7,0.8,0.9)$ & $(0.8,0.9,1.0,1.0)$ & $(0.8,0.9,1.0,1.0)$ & $(0.8,0.9,1.0,1.0)$ \\
$\mathrm{A}_{3}$ & $(0.6,0.7,0.8,0.9)$ & $(0.8,0.9,1.0,1.0)$ & $(0.6,0.7,0.8,0.9)$ & $(0.6,0.7,0.8,0.9)$ \\
$D 3$ & & & & \\
$\mathrm{~A}_{1}$ & $(0.8,0.9,1.0,1.0)$ & $(0.8,0.9,1.0,1.0)$ & $(0.6,0.7,0.8,0.9)$ & $(0.6,0.7,0.8,0.9)$ \\
$\mathrm{A}_{2}$ & $(0.6,0.7,0.80 .9)$ & $(0.8,0.9,1.0,1.0)$ & $(0.4,0.5,0.6,0.7)$ & $(0.8,0.9,1.0,1.0)$ \\
$\mathrm{A}_{3}$ & $(0.8,0.9,1.0,1.0)$ & $(0.4,0.5,0.6,0.7)$ & $(0.6,0.7,0.8,0.9)$ & $(0.8,0.9,1.0,1.0)$ \\
\hline
\end{tabular}

Table 12 Trapezoidal fuzzy number for system range of proactive maintenance strategies

\begin{tabular}{|c|c|c|c|c|}
\hline & $\mathrm{FR}_{111}$ & $\mathrm{FR}_{112}$ & $\mathrm{FR}_{113}$ & $\mathrm{FR}_{114}$ \\
\hline$A_{1}$ & $(0.60,0.70,0.80,0.90)$ & $(0.40,0.63,0.73,0.70)$ & $(0.40,0.57,0.67,0.70)$ & $(0.20,0.57,0.67,0.50)$ \\
\hline $\mathrm{A}_{2}$ & $(0.40,0.63,0.73,0.70)$ & $(0.40,0.70,0.80,0.70)$ & $(0.40,0.63,0.73,0.70)$ & $(0.40,0.70,0.80,0.70)$ \\
\hline \multirow[t]{2}{*}{$\mathrm{A}_{3}$} & $(0.20,0.57,0.67,0.50)$ & $(0.40,0.70,0.80,0.70)$ & $(0.20,0.57,0.67,0.50)$ & $(0.20,0.57,0.67,0.50)$ \\
\hline & $\mathrm{FR}_{121}$ & $\mathrm{FR}_{122}$ & $\mathrm{FR}_{123}$ & $\mathrm{FR}_{124}$ \\
\hline$A_{1}$ & $(0.40,0.63,0.73,0.70)$ & $(0.60,0.77,0.87,0.90)$ & $(0.40,0.77,0.87,0.70)$ & $(0.40,0.70,0.80,0.70)$ \\
\hline $\mathrm{A}_{2}$ & $(0.40,0.63,0.73,0.70)$ & $(0.20,0.63,0.73,0.50)$ & $(0.40,0.70,0.80,0.70)$ & $(0.60,0.70,0.80,0.90)$ \\
\hline \multirow[t]{2}{*}{$\mathrm{A}_{3}$} & $(0.40,0.57,0.67,0.70)$ & $(0.20,0.50,0.60,0.50)$ & $(0.40,0.57,0.67,0.70)$ & $(0.60,0.70,0.80,0.90)$ \\
\hline & $\mathrm{FR}_{131}$ & $\mathrm{FR}_{132}$ & $\mathrm{FR}_{133}$ & $\mathrm{FR}_{134}$ \\
\hline$A_{1}$ & $(0.40,0.70,0.80,0.70)$ & $(0.40,0.63,0.73,0.70)$ & $(0.60,0.77,0.87,0.90)$ & $(0.40,0.77,0.87,0.70)$ \\
\hline $\mathrm{A}_{2}$ & $(0.40,0.63,0.73,0.70)$ & $(0.20,0.50,0.60,0.50)$ & $(0.60,0.77,0.87,0.90)$ & $(0.60,0.70,0.80,0.90)$ \\
\hline \multirow[t]{2}{*}{$\underline{\mathrm{A}_{3}}$} & $(0.40,0.63,0.73,0.70)$ & $(0.40,0.70,0.80,0.70)$ & $(0.40,0.57,0.67,0.70)$ & $(0.40,0.63,0.73,0.70)$ \\
\hline & $\mathrm{FR}_{141}$ & $\mathrm{FR}_{142}$ & $\mathrm{FR}_{143}$ & $\mathrm{FR}_{144}$ \\
\hline$A_{1}$ & $(0.40,0.70,0.80,0.70)$ & $(0.60,0.83,0.93,0.90)$ & $(0.40,0.63,0.73,0.70)$ & $(0.40,0.57,0.67,0.70)$ \\
\hline $\mathrm{A}_{2}$ & $(0.40,0.63,0.73,0.70)$ & $(0.60,0.83,0.93,0.90)$ & $(0.40,0.63,0.73,0.70)$ & $(0.40,0.77,0.87,0.70)$ \\
\hline $\mathrm{A}_{3}$ & $(0.20,0.63,0.73,0.50)$ & $(0.40,0.63,0.73,0.70)$ & $(0.40,0.63,0.73,0.70)$ & $(0.40,0.70,0.80,0.70)$ \\
\hline
\end{tabular}


the different proactive maintenance strategies (Table 13). From Table $13, A_{3}\left(F R_{122}\right)$ and $A_{2}\left(F_{132}\right)$ had the lowest values of functional requirements. The crisp functional requirement value for $F_{142}\left(A_{1}\right.$ and $\left.A_{2}\right)$ had the highest values when compared with other crisp functional requirements values (Table 13). Proactive maintenance strategy $A_{1}$ had four crisp functional requirements values that were 0.68 , while six of the crisp functional requirements values for proactive maintenance strategy $A_{2}$ were 0.68 . The number of crisp function requirements values for proactive maintenance strategy $A_{3}$ that was 0.68 was five. The crisp functional requirement value for $\mathrm{FR}_{134}$ was the same for all the proactive maintenance strategies. Similarly, all the proactive maintenance strategies had the same crisp functional requirement value for $\mathrm{FR}_{143}$ (Table 13).

The expression in Eq. (6) was used to convert the information that is presented in Table 13 to information contents for the various proactive maintenance strategies (Table 14).

To determine the rank of each of the proactive maintenance strategy, the weights for each of the criterion and the total information content for each of the proactive maintenance strategy were considered (Table 15). It could be deduced that the most preferred proactive maintenance strategy for the case study is $A_{1}$ (Table 15).

The different values of $\lambda$ the rank of each of proactive maintenance strategy did not change (Table 16). Based on the WASPAS results, it could be deduced that the most preferred proactive maintenance strategy for the case study was $A_{1}$, while $A_{2}$ is the least preferred proactive maintenance strategy (Table 16). These results are consistent with those obtained from the FAD principle (Table 15).

\section{Contributions, managerial implications and limitations}

\subsection{Contributions to knowledge}

By relating research on maintenance strategy to rolling mills, the authors search to make contributions to maintenance management practice. First, despite a scanty but growing debate on maintenance strategy in other practice endeavours and fields such as wind turbine and thermal plants, there is substantially less effort on manufacturing processes and no work on rolling mills. The efforts committed by authors in this work extend previous research by revealing how uncertainty and imprecision can influence the selection of maintenance strategy in a rolling mill. Second, unlike previous debates, the theory and practice proposed here focus on rolling mills rather than textiles, palm oil and chemical producing plants. Rolling mills belong to the heavy material industry with many subsidiary products,

Table 13 Crisp functional requirements system range for proactive maintenance strategies

\begin{tabular}{|c|c|c|c|c|}
\hline & $\mathrm{FR}_{111}$ & $\mathrm{FR}_{112}$ & $\mathrm{FR}_{113}$ & $\mathrm{FR}_{114}$ \\
\hline \multicolumn{5}{|c|}{$F R_{11}$} \\
\hline$A_{1}$ & 0.75 & 0.68 & 0.62 & 0.62 \\
\hline$A_{2}$ & 0.68 & 0.075 & 0.68 & 0.75 \\
\hline \multirow[t]{2}{*}{$\mathrm{A}_{3}$} & 0.62 & 0.75 & 0.62 & 0.62 \\
\hline & $\mathrm{FR}_{121}$ & $\mathrm{FR}_{122}$ & $\mathrm{FR}_{123}$ & c \\
\hline \multicolumn{5}{|c|}{$F R_{12}$} \\
\hline$A_{1}$ & 0.68 & 0.82 & 0.82 & 0.75 \\
\hline $\mathrm{A}_{2}$ & 0.68 & 0.68 & 0.75 & 0.75 \\
\hline \multirow[t]{2}{*}{$\mathrm{A}_{3}$} & 0.62 & 0.55 & 0.62 & 0.75 \\
\hline & $\mathrm{FR}_{131}$ & $\mathrm{FR}_{132}$ & $\mathrm{FR}_{133}$ & $\mathrm{FR}_{134}$ \\
\hline \multicolumn{5}{|c|}{$F R_{13}$} \\
\hline$A_{1}$ & 0.75 & 0.68 & 0.82 & 0.82 \\
\hline $\mathrm{A}_{2}$ & 0.68 & 0.55 & 0.82 & 0.75 \\
\hline \multirow[t]{2}{*}{$\mathrm{A}_{3}$} & 0.68 & 0.75 & 0.62 & 0.68 \\
\hline & $\mathrm{FR}_{141}$ & $\mathrm{FR}_{142}$ & $\mathrm{FR}_{143}$ & $\mathrm{FR}_{144}$ \\
\hline \multicolumn{5}{|c|}{$F R_{14}$} \\
\hline$A_{1}$ & 0.75 & 0.88 & 0.68 & 0.62 \\
\hline$A_{2}$ & 0.68 & 0.88 & 0.68 & 0.82 \\
\hline$A_{3}$ & 0.68 & 0.68 & 0.68 & 0.75 \\
\hline
\end{tabular}


Table 14 Information content for the alternatives

\begin{tabular}{|c|c|c|c|c|}
\hline & $\mathrm{FR}_{111}$ & $\mathrm{FR}_{112}$ & $\mathrm{FR}_{113}$ & $\mathrm{FR}_{114}$ \\
\hline \multicolumn{5}{|c|}{$F R_{11}$} \\
\hline$A_{1}$ & 0.2630 & 0.1217 & -0.0116 & -0.0116 \\
\hline $\mathrm{A}_{2}$ & 0.1217 & 0.2630 & 0.1217 & 0.2630 \\
\hline \multirow[t]{2}{*}{$\mathrm{A}_{3}$} & -0.0116 & 0.2630 & -0.0116 & -0.0116 \\
\hline & $\mathrm{FR}_{121}$ & $\mathrm{FR}_{122}$ & $\mathrm{FR}_{123}$ & $\mathrm{FR}_{124}$ \\
\hline \multicolumn{5}{|c|}{$F R_{12}$} \\
\hline$A_{1}$ & 0.1217 & 0.3918 & 0.3918 & 0.2630 \\
\hline$A_{2}$ & 0.1217 & 0.1217 & 0.2630 & 0.2630 \\
\hline \multirow[t]{2}{*}{$\mathrm{A}_{3}$} & -0.0116 & -0.1844 & -0.0116 & 0.2630 \\
\hline & $\mathrm{FR}_{131}$ & $\mathrm{FR}_{132}$ & $\mathrm{FR}_{133}$ & $\mathrm{FR}_{134}$ \\
\hline \multicolumn{5}{|c|}{$F R_{13}$} \\
\hline$A_{1}$ & 0.2630 & 0.1217 & 0.3918 & 0.3918 \\
\hline$A_{2}$ & 0.1217 & -0.1844 & 0.3918 & 0.2630 \\
\hline \multirow[t]{2}{*}{$\mathrm{A}_{3}$} & 0.1217 & 0.2630 & -0.0116 & 0.1217 \\
\hline & $\mathrm{FR}_{141}$ & $\mathrm{FR}_{142}$ & $\mathrm{FR}_{143}$ & $\mathrm{FR}_{144}$ \\
\hline \multicolumn{5}{|c|}{$F R_{14}$} \\
\hline$A_{1}$ & 0.2630 & 0.4936 & 0.1217 & -0.0116 \\
\hline $\mathrm{A}_{2}$ & 0.1217 & 0.4936 & 0.1217 & 0.3918 \\
\hline $\mathrm{A}_{3}$ & 0.1217 & 0.1217 & 0.1217 & 0.2630 \\
\hline
\end{tabular}

Table 15 Total information index and ranks of proactive maintenance strategies

\begin{tabular}{lllllll}
\hline & $\mathrm{Ic}_{1}$ & $\mathrm{lc} \mathrm{c}_{2}$ & $\mathrm{lc} \mathrm{c}_{3}$ & $\mathrm{Ic}_{4}$ & $\mathrm{lc}_{\text {total }}$ & Rank \\
\hline Weights & 0.2509 & 0.1525 & 0.2908 & 0.3071 & & \\
$\mathrm{~A}_{1}$ & 0.3615 & 1.1682 & 1.1682 & 0.8668 & 3.5648 & 1 \\
$\mathrm{~A}_{2}$ & 0.7694 & 0.7694 & 0.5921 & 1.1288 & 3.2597 & 2 \\
$\mathrm{~A}_{3}$ & 0.2283 & 0.0554 & 0.4948 & 0.6281 & 1.4066 & 3 \\
\hline
\end{tabular}

Table 16 Maintenance strategies WASPAS results for different values of $\lambda$

\begin{tabular}{llllllllllll}
\hline & $Q_{i}^{1}$ & $Q_{i}^{2}$ & \multicolumn{1}{l}{$Q_{i}$} \\
\cline { 3 - 10 } & & $\lambda=0.1$ & $\lambda=0.2$ & $\lambda=0.3$ & $\lambda=0.4$ & $\lambda=0.5$ & $\lambda=0.6$ & $\Lambda=0.7$ & $\lambda=0.8$ & $\lambda=0.9$ \\
\hline $\mathrm{A}_{1}$ & 4.4395 & 0.7943 & 1.1588 & 1.5233 & 1.8879 & 2.2524 & 2.6169 & 2.9814 & 3.3459 & 3.7104 & 4.0749 \\
$\mathrm{~A}_{2}$ & 4.0889 & 0.8018 & 1.1305 & 1.4592 & 1.7879 & 2.1166 & 2.4453 & 2.7741 & 3.1028 & 3.4315 & 3.7602 \\
$\mathrm{~A}_{3}$ & 1.8091 & 0.3137 & 0.4633 & 0.6128 & 0.7623 & 0.9119 & 1.0614 & 1.2110 & 1.3605 & 1.5100 & 1.6596 \\
\hline
\end{tabular}

thereby making them major plants in which their performance could significantly affect other manufacturing outputs. Thus, this industry (rolling mill) may be used as test cases in a synergic analysis of the other subsidiary company's performance.

\subsection{Managerial implications}

The outcomes of this research provide some significant implications for maintenance managers and general managers of rolling mills. First, it appears that maintenance managers ought to be conscious of the various magnitudes of maintenance strategies in their plants and the implications that they have towards the attainment of manufacturing goals in their plants. They ought to appreciate that scientific and appropriate strategy selection tools for maintenance can significantly enhance the quality of their maintenance decisions and reduce the errors made in over- or under-estimating decision variables. As maintenance managers use multicriteria models to judge which maintenance strategy to adopt for the rolling mill, they should ascertain that the models incorporate the unique 
circumstance of uncertain activities of maintenance and the imprecise judgements of both themselves and the stakeholders they interact with to achieve manufacturing goals. To achieve the advantages of reliable decision making on maintenance strategy choice, the rolling mill maintenance manager and the general manager should ensure that there is increased interactions between them and all the relevant stakeholders (co-workers, suppliers of spares and government) to ensure that a thorough understanding of the strengths and limitations of stakeholders is taken into account during the formation of the uncertain aspects of the selection model.

This research again provides many important practical implications to the general manager that makes policy for the rolling mills. The outcomes of this research prove that although it is necessary to engage on predictive and reliability-based maintenance for the upkeep of the plant, embarking on a preventive maintenance scheme for the plant is crucial if the general manager would enhance the quality of performance in the rolling mill. Thus, the general manager should contribute more efforts to strengthen the preventive maintenance activities of the plant by the provision of additional resources and training of the maintenance personnel, thereby making the optimal usage of the workforce and the resources at the disposal of the general manager.

\subsection{Limitations and future work}

In the course of conducting this research, some knowledge was gained, which reveals the limitations of the methodology and research designs proposed in this article. With this insight, it is worthwhile to outline additional methods that could be pursued in future to extend the frontier of knowledge on maintenance strategy concerning rolling mills. There is room to enhance the study in future discussions in a variety of manners. First, the use of AHP and WASPAS are mainly for selection purposes but optimization is important in any process. However, this research has not considered this kind of data. Thus, future studies may analyse the role that optimisation plays in a concurrent optimization and selection of maintenance strategy for rolling mills. A few optimization kits may be interesting in the non-traditional optimization area: genetic algorithm, greedy heuristics, among others. Another path of research in the future relates to the sensitivity analysis of the important variables in a concurrent optimisation and selection process for maintenance strategy in rolling mills. Nowadays, the economy has a great impact on manufacturing activities and the incorporation of economic terms such as inflation and interest rate factors into the model that concurrently optimize and select maintenance strategy in a rolling mill is advocated. Furthermore, the outcomes of this research may fruitfully be complemented by research in similar industries but outside Nigeria such as rolling mills in India and China to track the dynamic influence of environmental and economic factors on the choice of maintenance strategy in a situation where optimization and selection of strategy are concurrently considered. Also, this research calls for a new theory concerning the introduction of uncertainty theory. In this work, the fuzzy axiomatic design has been applied. However, several other fuzzy theories may be applied. These are advocated for application in the context of selection only and the concurrent optimization and selection of maintenance strategy in a rolling mill.

\section{Conclusions}

The central problem tackled in this paper is that of selecting maintenance strategies in a manufacturing plant under uncertainty condition. This was achieved by the use of fuzzy logic theory embedded in fuzzy axiomatic design to develop an integrated model with analytic hierarchy process, while the selection of maintenance strategies in the manufacturing system was through the weighted sum-product evaluation.

The following issues are drawn as conclusions:

1. The proposed multicriteria model integrating $F A D$, AHP and WASPAS is an efficient methodology to select a maintenance strategy for a rolling mill.

2. The model indicates that preventive maintenance is preferred to the other two types (i.e. predictive and reliability-based maintenance).

3. It was observed that the reliability-based maintenance strategy was the least preferred maintenance strategy for the case study.

4. The results obtained from the proposed framework showed that the framework identified the level of priority that should be given to each type of proactive maintenance strategy for a manufacturing system.

The uniqueness of the proposed model is that the number of functional and design requirements in the proposed framework can be adjusted to suit many maintenance systems. Furthermore, the proposed framework could be applied to determine the service system proactive maintenance strategy with minor modifications.

An open issue that occurs from the paper here relates to the audience that filled the questionnaire. Two sub-issues arise here regarding the size of the questionnaire administered and the positions that the respondents occupy. In this work, three decision-makers were considered and 
the respondents were not top managers but middle-class managers. Although the respondents had decision-making responsibilities the strength of such responsibilities is not as strong as in the top management position. It is suggested that top management should be the target of such future administration of questionnaires and analysis and the number of respondents should be significantly enlarged. In this way, more reliable results may be obtained. Furthermore, the application of TOPSIS (technique to order preference by similarity to ideal solutions) to replace WASPAS could be useful to better understand the differences between models and the situations under which each model is best applicable.

\section{Compliance with ethical standards}

Conflict of interest The authors declare that they have no conflict of interest.

Ethical statement The procedures applied in this study involving human participants were in accordance with the ethical standards of the institutions of the authors. Participants' consents were obtained prior to the study.

\section{References}

1. Kumar R, Singh H (2018) Exploring the success factors for examining the potential of manufacturing system output. Benchmark Int J 25(4):1171-1193. https://doi.org/10.1108/BIJ-10-2016-0156

2. Kovalenko I, Tilbury D, Barton K (2019) The model-based product agent: a control-oriented architecture for intelligent products in multi-agent manufacturing systems. Control Eng Pract 86:105-117. https://doi.org/10.1016/j.conengprac.2019.03.009

3. Janardhanan MN, Nielsen P (2020) Optimisation of cost efficient robotic assembly line using metaheuristic algorithms. Eur J Ind Eng 14(2):247-264. https://doi.org/10.1504/EJIE.2020.105698

4. Lin Y-K, Chang P-C, Yeng LC, Shih P-S (2017) Reliability evaluation for an intermittent production system with stochastic number of normal machines. J Manuf Syst 45:222-235. https://doi. org/10.1016/j.jmsy.2017.10.002

5. Lyu Z, Lin P, Guo D, Huang GQ (2020) Towards zero-warehousing smart manufacturing from zero-inventory just-in-time production. Robot CIM Int Manuf. https://doi.org/10.1016/j. rcim.2020.101932

6. Huang D, Lv J (2020) Run-to-run control of batch production process in manufacturing systems based on online measurement. Comput Ind Eng. https://doi.org/10.1016/j.cie.2020.10629 8

7. Javid N, Khalili-Damghani K, Makui A, Abdi F (2020) Multi-objective flexibility-complexity trade-off problem in batch production systems using fuzzy goal programming. Expert Syst Appl. https://doi.org/10.1016/j.eswa.2020.113266

8. Subramaniyan C, Prakash SIV, Bhuvanesh N, Kalidasan B, Amarkarthik A (2020) Study based on the reduction of lot time by implementing set production and FMS in the traditional batch production system. Mater Today Proceed. https://doi. org/10.1016/j.matpr.2020.02.102
9. Zhang Y, Zhao M, Zhang Y, Pan R, Cai J (2020) Dynamic and steady-state performance analysis for multi-state repairable reconfigurable manufacturing systems with buffers. Eur J Oper Res 283(21):491-510. https://doi.org/10.1016/j.ejor.2019.11.013

10. Di Domizio G, Menghi R, Papetti A, Germani M, Marconi M (2019) A method for lean energy assessment of manufacturing systems. Procedia CIRP 81:1447-1452. https://doi.org/10.1016/j. procir.2019.03.314

11. Wang Z, Pang CK, Ng TS (2019) Robust scheduling optimization for flexible manufacturing systems with replenishment under uncertain machine failure disruptions. Control Eng Pract. https ://doi.org/10.1016/j.conengprac.2019.07.012

12. Chen $Y-Q$, Zhou B, Zhang M, Chen C-M (2020) Using loT technology for computer-integrated manufacturing systems in the semiconductor industry. Appl Soft Comput. https://doi. org/10.1016/j.asoc.2020.106065

13. Ratnayake RMC, Markeset T (2010) Technical integrity management measuring HSE awareness using AHP in selecting a maintenance strategy. J Qual Mainten Eng 16(1):44-630. https://doi. org/10.1108/13552511011030327

14. Momeni M, Fathi MR, Zarchi MK, Azizollahi S (2011) A fuzzyTOPSIS-based approach to maintenance strategy selection: a case study. Middle East J Sci Res 8(3):699-706

15. Jin H, Han F, Sang Y (2020) An optimal maintenance strategy for multi-state deterioration systems based on a semi-Markov decision process coupled with simulation technique. Mech Syst Signal Pr. https://doi.org/10.1016/j.ymssp.2019.106570

16. Wu T, Yang L, Ma X, Zhang Z, Zhao Y (2020) Dynamic maintenance strategy with iteratively updated group information. Reliab Eng Syst Saf. https://doi.org/10.1016/j.ress.2020.106820

17. Lu B, Zhou X (2017) Opportunistic preventive maintenance scheduling for serial-parallel multistage manufacturing systems with multiple streams of deterioration. Reliab Eng Syst Saf 168:116-127. https://doi.org/10.1016/j.ress.2017.05.017

18. Zhou X, Lu B (2018) Preventive maintenance scheduling for serial multi-station manufacturing systems with interaction between station reliability and product quality. Comput Ind Eng 122:283-291. https://doi.org/10.1016/j.cie.2018.06.009

19. Ilangkumaran M, Kumanan S (2009) Selection of maintenance policy for textile industry using hybrid multi-criteria decision making approach. J Manuf Technol Manag 20(7):1009-1022. https://doi.org/10.1108/17410380910984258

20. Ahmadi A, Gupta S, Karim R, Kummar U (2010) Selection of maintenance strategy for aircraft systems using multi-criteria decision making methodologies. Int J Reliab Qual Saf Eng. https ://doi.org/10.1142/502185393100037779

21. Bevilacqua $M$, Braghlia M (2000) The analytical hierarchy process applied to maintenance strategy selection. Reliab Eng Syst Saf 70(1):71-83. https://doi.org/10.1016/S0951-8320(00)00047-8

22. Arunraj NS, Maiti J (2010) Risk-based maintenance policy selection using AHP and goal programming. Saf Sci 48(2):238-247. https://doi.org/10.1016/j.ssci.2009.09.005

23. Labib AW (2014) A decision analysis model for maintenance policy selection using a CMMS. J Qual Mainten Eng 10(3):191-202. https://doi.org/10.1108/13552510410553244

24. Andrawus JA, Watson J, Kishk M, Adam A (2006) The selection of a suitable maintenance strategy for wind turbines. Wind Eng 30(6):471-486. https://doi.org/10.1260/030952406779994141

25. Cheng Y-H, Tsao H-L (2010) Rolling stock maintenance strategy selection, spare parts' estimation, and replacements' internal calculation. Int J Prod Econ 128(1):404-412

26. Sarkar A, Behera DK, Sarkar B (2011) The maintenance strategy selection of a gas turbine power plant system. J Inform Oper Manag 2(1):9-16

27. Goossens AJM and Basten RJI (2015) Exploring maintenance policy selection using analytic hierarchy process: an application 
to naval ships. Reliab Eng Syst Saf 142:31-41. https://doi. org/10.1016/j.ress.2015.04.014

28. Chemweno P, Morag I, Sheikhalishahi M, Pintelon L, Muchiri P, Wakiru J (2016) Development of a novel methodology for root cause analysis and selection of maintenance strategy for a thermal power plant: a data exploration approach. Eng Fail Anal 66:19-34. https://doi.org/10.1016/j.engfailanal.2016.04.001

29. Ding S, Kamaruddin S, Abdul-Azid I (2014) Maintenance policy selection model - a case study in the palm oil industry. J Manuf Technol Manag 25(3):415-435. https://doi.org/10.1108/ JMTM-03-2012-0032

30. Vishnu CR, Regikumar V (2016) Procedia Technology. Reliability based maintenance strategy selection in process plants: a case study, Procedia Tech 25:1080-1087. https://doi.org/10.1016/j. protcy.2016.08.211

31. Bashiri M, Badri H, Hejazi TH (2011) Selecting optimum maintenance strategy by fuzzy interactive linear assignment method. Appl Math Mod 35(1):152-164

32. Bertolini M, Bevilacqua M (2006) A combined goal programming-AHP approach to maintenance selection problem. Reliab Eng Syst Saf 91(7):839-848

33. Fouladgar MM, Yazdani-Chamzini A, Lashgari A, Zavadskas $K$, Turskis Z (2012) Maintenance strategy selection using AHP and COPRAS under fuzzy environment. Int J Strat Prop Manag. https ://doi.org/10.3846/1648715X.2012.666657

34. Gaonkar RSP, Farmagudi PG, Verma AK (2008) Exploring fuzzy set concept in priority theory for maintenance strategy selection problem. Int J Appl Manag Technol 6(3):131-142

35. Ilangkumaran M, Kumanan S (2012) Application of hybrid VIKOR model in selection of maintenance strategy. Int J Inform Syst Supp Chain 5(2):81

36. Jafari A, Jafarian M, Zareei A, Zaerpour F (2008) Using fuzzy delphi method in maintenance strategy selection problem. J Uncertain Syst 2(4):289-298

37. Pariazar M, Shahrabi J, Zaeri MS, Parhizi S (2008) A combined approach to maintenance strategy selection. J Appl Sci 8(23):4321-4329

38. Sagar MK, Jayaswal P, Kushwah K (2013) Exploring fuzzy SAW method for maintenance strategy selection problem of material handling equipment. Int J Curr Eng Technol 3(2):600

39. Wang L, Chu J, Wu J (2007) Selection of optimum maintenance strategies based on a fuzzy analytical hierarchy process. Int J Prod Econ 107(1):157-163

40. Zaeri MS, Shahrabi J, Pariazar M, Morabbi A (2007) A combined multivariate technique and multi-criteria decision making to maintenance strategy selection. In: 2007 international conference on Ind Eng Eng Manag, 2-4 Dec, pp 621-625

41. Zain S, Turkyilmaz A, Acar MF, Al-Turki U, Deminell OF (2012) Maintenance strategy selection using AHP and ANP algorithms: a case study. J Qual Mainten Eng 18(1):16-29

42. Saaty TL (2008) Decision making with the analytic hierarchy process. Int J Ser Sci 1(1):83-98

43. Suh NP (2001) Axiomatic design: advances and applications. Oxford University Press, New York

44. Khandekar AV, Chakraborty S (2015) Selection of material handling equipment using fuzzy axiomatic design principles. Informatica 26(2):259-282

45. Bojadziev G, Bojadziev M (2007) Fuzzy logic for business, finance and management, 2Ed. World Scientific, London
46. Girubha RJ, Vinodh S (2012) Application of fuzzy VIKOR and environmental impact analysis for material selection of an automotive component. Mater Des 37:478-486

47. Yeh RH, Kao K-C, Chang WL (2009) Optimal preventive maintenance policy for leased equipment using failure rate reduction. Comput Ind Eng 57(1):304-309

48. Dutoit C, Dehombreux $P$, Lorphèvre ER, Equeter L (2019) Statistical process control and maintenance policies for continuous production systems subjected to different failure impact models: literature review. Procedia CIRP 86:55-60

49. Duan C, Makis V, Deng C (2020) A two-level Bayesian early fault detection for mechanical equipment subject to dependent failure modes. Reliab Eng Syst Saf 193:106676

50. Jagtap HP, Bewoor AK, Kumar R (2020) Failure analysis of induced draft fan used in a thermal power plant using coordinated condition monitoring approach: a case study. Eng Fail Anal. https://doi.org/10.1016/j.engfailanal.2020.104442

51. Turan HH, Kosanoglu F, Atmis M (2020) A multi-skilled workforce optimisation in maintenance logistics networks by multithread simulated annealing algorithms. Int J Prod. https://doi. org/10.1080/00207543.2020.1735665

52. Prestwich R, Ho-Kim T-M (2009) Practical skills in international business: training needs for workforce competence by minnesota companies. J Teach Int Bus 20(2):149-173

53. Zhu S, van Jaarsveld W, Dekker R (2020) Spare parts inventory control based on maintenance planning. Reliab Eng Syst Saf 193:106600

54. Karabağ O, Eruguz AS, Basten R (2020) Integrated optimization of maintenance interventions and spare part selection for a partially observable multi-component system. Reliab Eng Syst Saf 20:106955

55. Alavian P, Eun Y, Liu K, Meerkov SM, Zhang L (2019) The (a, $\beta)$-precise estimates of MTBF and MTTR: definitions, calculations, and induced effect on machine efficiency evaluation. IFAC-PapersOnLine 52(13):1004-1009. https://doi.org/10.1016/j. ifacol.2019.11.326

56. Gonzalez E, Nanos EM, Seyr H, Valldecabres $L$, Yürüşen NY, Smolka U, Muskulus M, Melero JJ (2017) Key performance indicators for wind farm operation and maintenance. Energy Procedia 137:559-570

57. Yang S-J, Yang D-L (2010) Minimizing the total completion time in single-machine scheduling with aging/deteriorating effects and deteriorating maintenance activities Comput Math Appl 60(7):2161-2169

58. Yang S-J (2013) Unrelated parallel-machine scheduling with deterioration effects and deteriorating multi-maintenance activities for minimizing the total completion time. Appl Math Model 37(51):2995-3005

59. Chakraborty S, Zavadskas EK (2014) Application of WASPAS method in manufacturing decision making. Informatica 25(1):1-20

60. Zavadskas EK, Turskis Z, Antucheviciene J, Hajiagha SHR, Hashemi SS (2014) Extension of weighted aggregate sum product assessment with interval-valued intuition fuzzy numbers (WASPAS-IVIF). Appl Soft Comput 24:1013-1021

Publisher's Note Springer Nature remains neutral with regard to jurisdictional claims in published maps and institutional affiliations. 